\title{
Erken Çocukluk Sınıf Ortamı Değerlendirme Ölçeği Geçerlik ve Güvenirlik Çalışması*
}

Dilek Acer Çakar ${ }^{* *}$, Kaan Zülfikar Deniz ${ }^{* * *}$, Nergiz Teke ${ }^{* * * *}$, Tuğba Baş ${ }^{* * * * *}$, Emine

\author{
Kilınçc1 $^{* * * * * *}$, Nur Aksoy ${ }^{* * * * * * *}$
}

Geliş Tarihi: 08.07.2021 · Kabul Tarihi: 16.02.2022 · Çevrimiçi Yayın Tarihi: 16.02.2022

\section{$\ddot{\mathbf{O} z}$}

$\mathrm{Bu}$ araştırmanın amacı, Erken Çocukluk Sınıf Ortamı Değerlendirme Ölçeği'nin (EÇSODÖ) geliştirilmesi ve geçerlik-güvenirlik çalışmasının yapılmasıdır. Araştırmanın çalışma grubunu maksimum çeşitlilik örnekleme yoluyla belirlenen toplam 312 okul öncesi öğretmeni oluşturmaktadır. Öncelikle Temel Bileşenler Analizi (TBA) daha sonra Doğrulayıcı Faktör Analizleri (DFA) yapılmıştır. Güvenirlik analizleri için de Cronbach alfa iç tutarlılık güvenirliği hesaplanmıştır. Analizler sonucunda ölçeğin 38 madde ve 5 faktörden oluştuğu belirlenmiştir. Faktörler toplamda \%52.13 oranında ortak varyansı açıklamıştır. Analizler sonucunda ölçeğin uyum indeks değerleri (RMSEA=.076, S$\mathrm{RMR}=.025, \mathrm{GFI}=.67, \mathrm{AGFI}=.63, \mathrm{NFI}=.79, \mathrm{NNFI}=.89, \mathrm{CFI}=.90, \mathrm{IFI}=.90)$ incelendiğinde GFI, AGFI, NFI değerleri zayıf uyuma karşılık gelirken NNFI, CFI, IFI' nın iyi uyuma karşılık geldiği görülmektedir. Cronbach alfa iç tutarlık katsayıları sırasıyla $.86, .84, .74, .66$ ve .84 olarak belirlenmiştir. Bu doğrultuda geçerli ve güvenilir bir ölçek elde edilmiştir.

Anahtar sözcükler: erken çocukluk, sınıf ortamı, ortam değerlendirme, geçerlik, güvenirlik

Atıf:

Çakar, D.E, Deniz, K.Z., Teke, N., Baş, T., Kılınçcı, E. ve Aksoy, N. (2022). Erken çocukluk sınıf ortamı değerlendirme ölçeği geçerlik ve güvenirlik çalışması. Pamukkale Üniversitesi Ĕgitim Fakültesi Dergisi, 56, 1-34, doi:10.9779.pauefd.961254

\footnotetext{
* VIII. Uluslararası Avrasya Eğitim Araştırmaları Kongresi’nde (7-10 Temmuz 2021, Aksaray, Türkiye) sözlü bildiri olarak sunulmuştur.

** Prof. Dr., Ankara Üniversitesi, Eğitim Bilimleri Fakültesi, https://orcid.org/0000-0002-0608-2073, dilekacer@yahoo.com (Sorumlu Yazar)

**** Doç. Dr., Ankara Üniversitesi, Eğitim Bilimleri Fakültesi, https://orcid.org/0000-0003-0920-538X, zlfkrdnz@yahoo.com

**** Arş. Gör., Bartın Üniversitesi, Eğitim Fakültesi, https://orcid.org/0000-0002-7281-7509, nergizteke42@gmail.com

${ }^{* * * * *}$ Arş. Gör., Bartın Üniversitesi, Eğitim Fakültesi, https://orcid.org/0000-0003-1093-2445, tugbakarakoc32@,gmail.com

******* Doktora Öğrencisi, Wisconsin-Madison Üniversitesi, Eğitim Fakültesi, https://orcid.org/0000-0002-3848-0404, kilincci@wisc.edu

******** Arş. Gör., Kafkas Üniversitesi, Eğitim Fakültesi, https://orcid.org/0000-0002-8693-0588, nur.aksoy93@gmail.com
} 


\section{Giriş}

Çocuğun gelişiminin büyük oranda 0-8 yaş aralığında tamamlandığını belirten pek çok araştırma bulunmaktadır (Bjorklund ve Causey, 2017; Brodin ve Renblad, 2019; McGurk, 2017). Oldukça kritik olan bu yaş aralığında çocuğun gelişiminin sağlıklı olabilmesi için dikkat edilmesi gereken hususların başında çocuğa zengin uyarıcılarla dolu bir çevre içinde keşfetme ve öğrenme ortamlarının sağlanması gelmektedir (Broekhuizen, Mokrova,, Burchinal, GarrettPeters ve Family Life Project Key Investigators, 2016; Mashburn, Pianta, Hamre, Downer, Barbarin, Bryant ve Howes, 2008). Öğrenme ortamının etkililiği doğrudan çocukların öğrenme ve gelişim sürecindeki bilişsel, sosyal ve duygusal kazanımlarını, akademik başarılarını, benlik saygılarını ve öğrenmeye karşı tutumlarını etkilemektedir (Belfield, Nores, Barnett ve Schweinhart, 2005; Broekhuizen ve diğerleri, 2016; Gagnon, Kidder-Ashley ve Nickerson, 2017; Mashburn ve diğerleri, 2008; Obaki, 2017; Parshekofti, 2014; Sheridan ve Pramling Samuelsson, 2013). Mohamed ve Marzouk (2016) tarafindan yapılan bir çalışmada da fiziksel açıdan uygun okul öncesi sınıf ortamları, çocukların sosyal becerileri, akran etkileşimleri, çocuk-öğretmen etkileşimi ve sınıf etkinliklerine katılım ve iş birliği ile ilişkilendirilmiştir. Ayrıca, bu sınıf ortamlarında dikkat problemleri, saldırganlık sorunları, depresyon ve duygusal kontrol sorunları gibi problemlerin daha az ortaya çıktığı bulunmuştur. Öğrenme ortamlarının çocuğun sosyal (Obaki, 2017), dil, duygusal, bilişsel gelişiminde (Choi, Van Merriënboer ve Paas, 2014) ve öğrenmelerinde (Che Ahmad ve Amirul, 2017; Parshekofti, 2014) kritik rolünün bulunduğu ve bu nedenle özenle hazırlanması gerektiği bilinmektedir. Çocuğa, gerekli yaşam becerilerini öğrenirken, olumlu davranışları kazanması için güvenli, rahat ve zengin bir ortamın sağlanması oldukça önemlidir.

İyi hazırlanmış öğrenme ortamlarının çocukların gelişimlerine, öğrenme isteklerine, ilgilerine ve uzun vadede akademik becerilerine önemli katkılarının olduğu bilindiğinden öğrenme ortamlarının değerlendirilmesi önemlidir (Gagnon, Kidder-Ashley ve Nickerson, 2017). Bu değerlendirilmelerin yapılması için en güvenli yollardan olan standardize edilmiş araçlar, öğrenme ortamındaki önemli değişkenlerin güçlü ve zayıf yönlerini belirlemede yardımcı olmakta, yapılacak iyileştirilmelerin kolaylaştııılmasını ve çocukların gelişimleri ile öğrenmelerinin desteklenmesini sağlamaktadır (Hui, Lee, Yeung, Chick, Ho ve Ng, 2017). Bu bağlamda, bu çalışmada, Türkiye'deki okul öncesi programı ve ortamlarını değerlendirmeye daha uygun bir Erken Çocukluk Sınıf Ortamı Değerlendirme Ölçeği (EÇSODÖ) geliştirmeyi ve bu ölçeğin geçerlilik ve güvenirlik analizini yapmayı amaçlanmıştır. 


\section{Öğrenme Ortamının Önemi}

Öğrenme ortamı öğrenenin bilgiyi öğrendiği ve yorumladı̆̆ 1 , akran ve yetişkinlerle etkileşim kurduğu, materyal ve araçları kullandığı bir ortam olarak tanımlanmaktadır. Öğrenme ortamı, öğrenmenin gerçekleştiği ve öğrenenin durum ya da olayları anlamlandırmak ve soruna anlamlı çözümler bulmak için kaynakları kullanabildiği sosyal, psikolojik ve pedagojik içeriklerden oluşan ortamdır (Ozkal, Tekkaya, Cakiroglu ve Sungur, 2009; Sandberg, 2017; Wilson, 1996). Okul öncesi eğitim sınıf ortamlarında çocukların öğretmenlerle yakın bir etkileşim içinde bulunduğu görülmektedir. Bu nedenle, sınıf ortamında okul öncesi öğretmenlerinin çocuklara gerekli olan fiziksel ve sosyal ortamı sağlayarak destek olması oldukça önemlidir. Çocuk yaş ve gelişim özelliklerine bağlı olarak ortamı daha ayrıntılı tanımaya başlamaktadır. Çocuğun ihtiyaçlarına uygun olarak hazırlanan ortamlar çocuğun, bağımsız, özgüveni ve özsaygısı yüksek bireyler olmasına destek sağlamaktadır (Demiriz, Karadağ ve Ulutaş, 2003). Çocuğun öğrenme ortamı; sosyal ve fiziksel ortam olarak iki şekilde ele alınmaktadır (Weinstein, 1979; Roeser, Midgley, ve Urdan, 1996). Sosyal ortam, bireyler ve çocuğun onlarla kurduğu ilişkilerden, fiziksel ortam ise, yapı ve kullanılan materyallerden oluşmaktadır. Çocuğun içinde yer aldığg hem sosyal hem de fiziksel ortam, çocuğun gelişiminde önemli rol oynamaktadır. Çeşitli uyarıcılar yoluyla duyuları harekete geçiren bir ortam, çocuğun zihinsel gelişimine katkı sağlayarak çocuğun empati, fikir üretme ve yaratıcılık becerilerini de geliştirebilir (Gültekin Akduman, 2010). Havu-Nuutinen ve Niikko (2014)'a göre okul öncesi öğrenme ortamı; fiziksel-estetik, psiko-sosyal ve pedagojik-etik olmak üzere üç boyutta tanımlanmaktadır. Fiziksel-estetik ortam, çocuklar ve öğretmenler için eğlence ve estetik deneyimlerini yerine getirebilecek şekilde doğal malzemelerden inşa edilmiş çevreyi içermektedir. Psiko-sosyal ortam, çocukların meraklarını, ilgilerini, öğrenme motivasyonlarını, etkinliklerini ve kendilerini yönlendirmelerini teşvik eden kabul edici bir çevreyi ifade etmektedir. Pedagojiketik ortam ise, öğretme ve etkinlik organizasyonunu, eğitim ilkelerini, bakım ve müfredat uygulamalarını kapsamakta ve davranışların etik boyutlarını dikkate alarak öğretmenin öğretme bakış açısını, çocuklar ve ebeveynleri ile etkileşimini içermektedir.

Ortamın fiziksel olarak düzenlenmesi, çeşitli tercihler için çeşitli aktiviteleri teşvik ederek çocukların davranışlarını ve seçimlerini yönlendirmektedir. Kaliteli mekansal ve estetiksel niteliklere sahip, güvenli, uygun malzeme ve mobilya kullanılarak tasarlanmış okul öncesi ortamları, öğretme ve öğrenme için elverişli olmakta ve çocuğun gelişimini ve öğrenüvenlimesini en üst seviyeye çıkarmaktadır (Shaari ve Ahmad, 2016). Zamani (2016)'nin çalışmasında, doğal ve yapay unsurların birlikte bulunduğu ortamlardaki erişilebilir doğal 
4 D.E., Çakar, K.Z., Deniz, N. Teke, T. Baş, E. Kılınçcı ve N, Aksoy/ Pamukkale Üniversitesi Eğitim Fakültesi Dergisi, 56, 1-34, 2022 malzemelerin, çocukların keşfetmesi, fen öğrenimi ve dramatik oyunları için önemli olduğu vurgulanmaktadır. Örneğin, Türkiye'de okul öncesi eğitim kurumlarında kullanılmakta olan 2013 Okul Öncesi Eğitim Programı'nın (MEB, 2013) geliştirilmesinde temel alınan yaklaşımlardan biri olan High-Scope Yaklaşımı'na göre hem bireysel hem grup oyunları için yeterli sayıda ve çeşitlilikte açık uçlu materyallerin yer alması gerekmektedir. Bu materyallerin çocuğun boyuna uygun raflarda ve şeffaf kaplar içinde bul-kullan-yerine yerleştir ilkesi doğrultusunda düzenlenmiş olması önemlidir (Wiltshire, 2018). Yetişkinlerin ve çocukların sınıf içinde birbirlerini rahatlıkla görebilecekleri, etkileşime girebilecekleri ve çocukların ilgileri doğrultusunda çalışabilecekleri öğrenme merkezleri düzenlenmesi önemlidir (Aktulun ve Kiziltepe, 2018; Kostelnik, Soderman, Whiren, Rupiper, 2015). High Scope Yaklaşımına göre, çocukların erişebileceği materyalleri saklamak ve sergilemek için öğrenme merkezleri/alanlar, çocuk boyuna uygun, mobilya ve hatta çit gibi çeşitli eşyalar kullanılarak bölünmelidir. Bölmeyi sağlayan materyaller çok yüksek olmamalı, böylece çocuklar arkadaşlarını izleyebilmeli ya da bir sonraki oynamak istedikleri yeri görebilmeli ve öğretmen de çocukları görebilmelidir. Öğrenme merkezleri/alanlar için kullanılacak etiketler yalnızca orada bulunanları tanımlamakla kalmayıp aynı zamanda çocuklara uygun ifadelerle yazılmış ya da sembol kullanılarak ifade edilmiş olmalıdır. Öğrenme merkezlerine/alanlara, çocuklar için anlam ifade eden ve merkezin ne olduğunu açıklayan bir isim verilmesi, çocukların kendi oyunlarını kontrol etmelerini ve bağımsızlık geliştirmelerini sağlamaktadır (Holt, 2010). Öğrenme merkezlerinde yer alan materyaller, doğayı sınıf ortamına taşıyacak nitelikte olmalıdır. Örneğin, etkinliklerde yaprak, toprak, dal, kabuk, taş ve su gibi doğal materyaller kullanılması önemlidir. Doğal materyallerin yanında sınıf ortamında hoş renk ve dokuların yer almasına özen gösterilmelidir (Şahin, 2010).

Özenle tasarlanmış bir fiziksel ortam çocukların seçimlerini ve keşiflerini etkilemekte, inisiyatif alma, özerlik ve sosyal beceri gelişimleri ile kendi eylemlerinin ve sorumluluklarının kontrolünü alabilme yetkinliklerini desteklemektedir (Botsoglou, Beazidou, Kougioumtzidou ve Vlachou, 2019). Çocuklar kendi başına hareket edebilecekleri ve bağımsız olarak ya da gruplar halinde çalışabilecekleri bir diğer deyişle hem sosyal etkileşim kurabilecekleri hem de bireyselliklerini yaşayabilecekleri, kendilerini ait ve güvende hissedebilecekleri, materyallere rahatlıkla ulaşabilecekleri, esneklik ve akıcılık içeren bir ortamda daha rahat öğrenmekte ve eğitim sürecine daha kolay dahil olabilmektedir (Lim ve Bahauddin, 2019; Knauf, 2019, Spencer, 2006, Tadjic, Martinec ve Farago, 2017). Doğal ortamlar, çocukları sosyalleşmeye ve çeşitli oyun etkinliklerine katılmaya teşvik etmektedir (Azlina ve Zulkiflee, 2012). 
Eğitim ortamının diğer boyutları ile ilgili olarak, sosyal çevre bireylerden ve çocuğun onlarla olan ilişkilerinden, fiziksel çevre ise kullanılan yapı ve malzemelerden oluşmaktadır. Vygotsky, çocuğun bilişsel gelişimi için sosyal çevresinin önemli olduğunu belirtmektedir. Çocukların öğrenmesinin kaynağını onların yakın sosyal çevresi olarak tanımlar. Vygotsky'ye göre, bir çocuğun sınıf içindeki yakınsak gelişim alanı, öğretmen tarafından kurulan ve yürütülen yapı iskeleleri aracılığıyla geliştirilebilir. Çocuğun destek alarak yapabilecekleri ve destek almadan yaptıkları beceriler değişiklik gösterebilmektedir. Çocuğun süreçte destek alarak yapabilecekleri ilerleyen dönemlerde çocuğun bağımsız olarak yapabileceklerine dönüşmektedir (Bodrova ve Leong, 2017). Vygotsky (1978)'e göre, çocuklar, diğerlerinin davranışlarını gözleyerek düzenlemektedir. Kuralları kendileri uygulamadan önce diğerlerinin üzerinde uygulamaktadırlar ve düzenleme becerisi öğretmen ya da ebeveyn gibi daha yetenekli bir kişi tarafından gerçekleştirildiğinde çocuğun öz düzenlemesine rehberlik etmektedir. High Scope yaklaşımı etkin öğrenmeyi temel almakta ve bu doğrultuda çocukların bağımsız hareket edecekleri, deney yapabilecekleri, arkadaşlarıyla çalışabilecekleri, kendilerine ait özel bir çalışma alanının olması gerektiği fikrini savunmaktadır (Epstein ve Schweinhart, 2018; Hohmann ve Weikart, 2000). Böylece çocukların sınıf ortamını benimseme, plan yapma ve planları doğrultusunda uygun aracı seçebilme davranışları (Arıkan, 2016) ile kullandığı materyali yerine geri koyarak öz düzenleme becerilerinin gelişmesine katkıda bulunmaktadır.

Öz düzenleme gibi bireysel yeterlilikle ilişsilendirilebilecek bir diğer beceri türü öz yeterliliktir. Bireyler, kendilerine gelişim düzeylerinde sunulan tekrarlı deneyimler yoluyla kendi yeteneklerinin farkına varabilir ve böylece olumsuzluklardan etkilenmeden başarısız oldukları deneyimlerin üstesinden gelebilmektedir (Bandura, 1989). Öz yeterlik, sınıf ortamının bileşenlerine bağlıdır çünkü bir öğrenme ortamının düzeni ve açıklığı, yeteneklerin daha doğru bir şekilde değerlendirilmesine izin vermektedir (Lorsbach ve Jinks, 1999). Öğrenmeyi teşvik etme kabiliyetine sahip öğretmenler, öğrencileri için ustalık deneyimleri yaratabilmekte, ancak öğretim etkinlikleri konusunda kendilerinden kuşku duyan öğretmenler, öğrencilerin yeteneklerini ve bilişsel gelişimlerini olumsuz yönde etkileyebilecek sınıf ortamları oluşturabilmektedirler (Bandura, 1995). Ayrıca, öğretmen sadece kazanılacak davranış ve öğrenme için değil aynı zamanda çocuğu amacına ulaşması için güdüleyebilir ve liderlik becerisinin gelişmesini sağlayabilir (Şahin, 2010). Bu sayede Bandura'nın davranışların şekillenmesinde önemli olabileceğini savunduğu öz yeterlik algısının yüksek olmasına da katkıda bulunabilir. Çocukların öz yeterlik algısının yüksek olması için öğretmenin çocukların 
6 D.E., Çakar, K.Z., Deniz, N. Teke, T. Baş, E. Kılınçcı ve N, Aksoy/ Pamukkale Üniversitesi Eğitim Fakültesi Dergisi, 56, 1-34, 2022 bireysel ihtiyaçlarını dikkate alması, gelişim düzeylerine uygun çeşitli etkinliklere yer vermesi, sınıf ortamında çocukları kıyaslamadan iş birliğini desteklemesi önemlidir (Senemoğlu, 2015).

Çocuklar, bazı durumlarda iş birliği ve etkileşim kurmadan sadece gözlem yaparak da öğrenebilmektedir. Gözlem yoluyla öğrenmede en önemli öğe modeldir. Bandura (1977)'ya göre, çocuk, gözlediği model davranışları pekiştirilme durumlarına göre gösterme eğilimindedir. Bu nedenle öğretmen, çocukların olumlu davranışlarına pekiştireçler vererek diğer çocuklara bu davranışın uygun ya da uygun olmadığı mesajını ileterek çocukların olumlu davranışları edinmesini sağlayabilmektedir (Trawick-Swith, 2014). Çocukların olumlu davranışları kazanmaları ve başarma duygusunu tatmaları için öğretmenin uygun ortam ve firsatlar sunması gerekmektedir.

\section{Öğretmenin Rolü}

Ekolojik Kuram'a göre gelişim çocuğun çevreyle olan etkileşiminin bir ürünüdür (Bronfenbrenner, 1994). Gelişim sürecinde çocukların karşı karşıya kaldıkları değişik durum ve bağlamlara ve çocukların bu bağlamlardaki rolleriyle etkileşimlerine odaklanılır (Özgün, 2015). Çocuğun, merkezinde yer aldığı çevreyle iletişime geçmesi ve çevreden gelen etkilere tepki vermesini sağlayan çevrenin bilişsel, sosyal, duygusal, biyolojik ve psikolojik karakterinin olduğu öne sürülmüştür (Erdiller, 2010). Ekolojik Kuram’daki beş sistemden biri olan mikrosistem, çocuğun yakın çevresindeki faktörleri, karşılaştıkları günlük olayları ve insanlarla ilişkilerini içermektedir. Öğretmenler bu sistemin içindedir ve çocukların ilgi alanları doğrultusunda becerilerini geliştirebilecekleri ve yeni öğrenmeler gerçekleştirebilecekleri ortamların hazırlanmasında en önemli faktörlerden biri öğretmenin rolüdür (Bronfenbrenner, 1976; Bronfenbrenner, 1994). Goble, Hanish, Martin, Eggum-Wilkens, Foster ve Fabes'1n (2016) yaptığı bir çalışmada öğretmenin sınıf etkinliklerinde çocuklarla doğrudan etkileşime geçmesinin kelime gelişimi, matematik ve sosyal beceriler başta olmak üzere çocukların genel gelişimlerine olumlu katkıları olduğu bulunmuştur.

Vygotsky’e göre öğretmen, sınıf içinde çocukların oyunlarına katılan, problem durumlarında çocukların problemi çözmelerine rehberlik eden, çocukların hem bağımsız hem de akranlarıyla birlikte etkinliklere katılmalarını teşvik eden, uygun davranışlar için model olan, çocukların öğrenmeleri için uygun gördüğü yöntem ve teknikleri uygulayan ve bu yöntem ve teknikler başarılı olmazsa çocukların öğrenme tutumunu ve sonuç olarak da öğrenme sonuçlarını değiştirmek için onları doğru yönde değiştiren bir konumda olmalıdır (Kravtsova, 2017). Öğretmen aynı zamanda çocukların birbirinden öğrenmesine ve birbirleri ile etkileşim kurmalarına imkân sağlamalıdır (Stanulis ve Manning, 2002). Böylece çocuk hem öğretmen 
hem de akranlarıyla kurduğu etkileşim yoluyla bilmediklerini öğrenmekte ve bildikleri konusunda da daha yetkin hale gelebilmektedir. Fiziksel ortama ilişkin eksiklikler programın uygulamasında sorun yaratmakta ancak öğretmenlerin mesleki yeterlilikleri ve niteliği, ortama ilişkin yetersizliklerin üstesinden gelmede önemli bir role sahip olmaktadır. Öğrenme ortamlarının yetersizliğinin öğretmenlerin yapabilecekleri uygulamalar ve düzenlemelerle iyileştirilebileceği düşünülmektedir (Babaroğlu, 2018).

\section{Okul öncesi eğitim ortamının değerlendirilmesi}

Çalışma kapsamında yapılan alan yazın taramasında, çocukların eğitimi, gelişimi ve öğrenmesi için hazırlanan eğitim ortamlarının yeterliliğini değerlendirmek için geliştirilmiş çeşitli standartlaştırılmış araçlar olduğu görülmüştür. Bu araçlardan biri de Maxwell (2007) tarafından geliştirilen Sınıf Derecelendirme Ölçeği'dir (Classroom Rating Scale) (CRS). Maxwell (2007) bu ölçeği, sınıfın fiziksel ortamı ile çocukların bilişsel yeterlikleri arasındaki olası ilişkiyi ortaya koymak için geliştirmiştir. Ayrıca Kragh-Müller ve Ringsmose (2015) tarafından geliştirilen Kvalitet I Dagtilbud - Okul Öncesi Kalite Ölçeği (Quality in Preschool Scale) (KIDS), Danimarka/İskandinav kültürel bağlamına göre oluşturulmuştur ve sosyal ilişskiler, fiziksel çevre, oyun ve etkinlikler gibi alanlara odaklanarak okul öncesi eğitim kurumlarında eğitimin kalitesini ve günlük uygulamaları değerlendirmek için kullanılmaktadır. Ek olarak, Hyson, Hirsh-Pasek ve Rescorla (1990) tarafindan hazırlanan Sınıf Uygulamaları Envanteri (Classroom Practices Inventory) (CPI), erken çocukluk sınıfını müfredat/etkinlik odağı ve duygusal iklim açısından güvenilir gözlemler ile ölçmek için geliştirilmiştir. Diğer taraftan, Sınıf Sistemleri Gözlem Ölçeği (Classroom Systems Observation Scale) (CSOS), okul öncesi eğitimden altıncı sınıfa kadar sınıfların işleyiş̧ini gözlem yoluyla değerlendirmek için kullanılan bir araçtır. CSOS, sınıf uyumu (duygusal bağ, destekleyicilik, sınırlar), sınıf esnekliği (liderlik, disiplin, müzakere) ve sınıf iletişimi (dinleyicinin becerileri, kendini açma, netlik) olmak üzere üç boyuttan oluşmaktadır. Pianta, La Paro ve Hamre (2008) tarafından geliştirilen Sınıf Değerlendirme Puanlama Sistemi (The Classroom Assessment Scoring System) (CLASS) ise, okul öncesinden üçüncü sınıfa kadar sınıf kalitesini değerlendirmek için kullanılan bir gözlem aracıdır. Bu araç, duygusal destek, sınıf düzeni ve öğretim desteği olmak üzere üç alandan oluşmaktadır. Erken Çocukluk Ortamı Derecelendirme Ölçeği'nde de (Early Childhood Environment Rating Scale) (Harms, Clifford ve Cryer, 2005), erken çocukluk ortamlarının kalitesi gözlemler yoluyla değerlendirilmektedir. Bu ölçek, mekân ve mobilyalar, kişisel bakım rutinleri, dil ve okuryazarlık, öğrenme etkinlikleri, etkileşim ve program yapısını içeren altı alt ölçekten oluşmaktadır. Sonuç olarak okul öncesi öğrenme ortamını değerlendirmek için 
8 D.E., Çakar, K.Z., Deniz, N. Teke, T. Baş, E. Kılınçcı ve N, Aksoy/ Pamukkale Üniversitesi Eğitim Fakültesi Dergisi, 56, 1-34, 2022 geliştirilmiş birçok ölçeğin olduğu, ancak bu ölçeklerin farklı eğitim programlarına göre hazırlandığı görülmektedir. Ayrıca Türkçe alanyazında erken çocukluk eğitim ortamını değerlendirmek için kullanılan ölçeklerin yabancı kaynaklardan uyarlandığı belirlenmiştir (Solak, 2007).

\section{Türkiye'de Okul Öncesi Eğitim ve Güncel Araştırma}

2013 yılında Türkiye'de uygulanan okul öncesi programı güncellenerek ülke genelinde MEB'e bağlı okul öncesi eğitim kurumlarında uygulanmaya başlamıştır. Bu programda çocukların tüm alanlarda sağlıklı gelişim sağlaması, ilkokula hazırlanması amaçlanarak şartları elverişsiz çevrelerden gelen çocuklar için ortak, kaliteli eğitim ortamları yaratmak ve Türkçe'yi doğru ve güzel konuşmaları amaçlanmaktadır. Programda bilişsel, motor, dil, sosyal ve duygusal gelişim, özbakım alanlarından kazanım ve göstergeler temel alınmıştır. Çocukların bu alanlarda kazanımları elde etmeleri için okul öncesi eğitim kurumları ve öğretmenlerin zengin uyarıcılı, gelişimsel, esnek, oyun temelli çocuk merkezli bir ortam ve etkinlikler hazırlaması önem kazanmaktadır (MEB, 2013). Özsırkıntı, Akay ve Yılmaz Bolat (2014) tarafından gerçekleştirilen araştırmada da, çalışmaya dâhil edilen öğretmenlerin 2013 MEB Okul Öncesi Eğitim Programı'nı öğrenci merkezli, esnek ve aktif öğrenme sağlayan bir program olarak değerlendirdiği sonucuna ulaşılmıştır. Bu program aynı zamanda dünyadaki birçok programın farklı yönlerini içine alarak eklektik bir yapı kazanmıştır. Bunun gerekçesi 21.yy da sağlıklı ve üretken bireyler yetiştirmek için gerekli öğrenme ortamlarını oluşturmaktır. Tuğluk ve Özkan (2019) tarafından gerçekleştirilen araştırmada MEB 2013 Okul Öncesi Eğitim Programında sosyal-duygusal, bilişsel ve dil gelişim alanında 21. yy becerilerine ilişkin yer alan kazanımların programın tamamında bulunan kazanımların \%25.9'unu oluşturduğu görülmektedir. Programda, sınıflarda çocukların öğrenme deneyimlerini zenginleştirmeye ve farklı gereksinimlerini karşılamaya yönelik olarak kazanım ve göstergeler doğrultusunda hazırlanması beklenen blok, dramatik oyun, sanat, kitap fen, müzik gibi öğrenme merkezlerinde ilgi çekici materyalleri barındırması gerekmektedir (MEB, 2013). Ülkenin genel koşulları düşünüldüğünde henüz bu ortamların tüm çocuklar için uygun koşullarda sağlanamadığı tespit edilmiştir (Güçlü ve Altan, 2020; Kubanç, 2014; Karaküçük, 2008; Çobanoğlu, Yıldırım ve Aydın, 2020). Kaliteli eğitim, uygun ve kaliteli ortamlarda gerçekleştirilebileceğinden okul öncesi eğitim kurumlarında sınıf ortamlarının ne denli yeterli olduğunun MEB 2013 Programı hedefleri ve sınıf ortamı için sunduğu ideal ilkeler doğrultusunda değerlendirilmesi gerekmektedir. Türkiye'de okul öncesi eğitim kurumlarındaki sınıf ortamlarını, uygulanan program çerçevesinde değerlendirebilecek Türk kültürü ve eğitim yapısıyla örtüşen bir ölçme 
aracının gerekliliği ortaya çıkmıştır. Ayrıca, alan yazında yer alan ve Türk kültürüne uyarlanan ölçeklerde okul öncesi sınıf ortamının gözlemler aracılığıyla dışarıdan bir bakışla değerlendirildiği görülmüştür. Ancak, sınıfın öznesi olan öğretmenin kendi uzmanlık alanında yaptığı değerlendirmeler önemlidir. Böyle bir aracın geliştirilmesi çocukların sınıf ortamından daha iyi faydalanabilmesi için öğretmenlerin, sınıf ortamının niteliğini değerlendirip çocukların ihtiyaçlarını karşılayabilecek şekilde uygulanan program çerçevesinde düzenleme yapmalarına katkı sağlayacaktır. Bu doğrultuda araştırmacılar tarafından Erken Çocukluk Sınıf Ortamı Değerlendirme Ölçeği'nin (EÇSODÖ) geliştirilmesi ve geçerlik-güvenirlik çalışmasının yapılması amaçlanmıştır.

\section{Yöntem}

\section{Araştırmanın Modeli}

Araştırma, nicel araştırma yöntemlerinden tarama modelinde yürütülmüştür. Tarama modeli, bir grubun spesifik özelliklerini (yetenekler, tutumlar, inançlar ve / veya bilgi gibi) ya da grubun belirli bir konu hakkındaki görüşlerini belirlemeyi içermektedir (Fraenkel ve Wallen, 2009). Bu araştırmada Türkiye'deki okul öncesi eğitim kurumlarındaki sınıf ortamının özelliklerini değerlendirmeye yönelik geçerli ve güvenilir bir ölçme aracı geliştirmeye yönelik olarak tarama modelinde bir araştırma yürütülmüştür.

\section{Çalışma Grubu}

$\mathrm{Bu}$ araştırmanın çalışma grubunu, maksimum çeşitlilik örnekleme yoluyla belirlenen 20182019 eğitim öğretim yılında Türkiye'de yer alan ve Milli Eğitim Bakanlığı'na bağlı devlet ve özel anaokullarında çalışan 312 okul öncesi öğretmeni oluşturmaktadır. Maksimum çeşitlilik örneklemde, evrende yer alan ve alt grupların kendi içinde benzerlik gösterdiği grupların seçilmesi söz konusudur (Büyüköztürk, Kılıç Çakmak, Akgün, Karadeniz ve Demirel, 2016). $\mathrm{Bu}$ amaçla, Türkiye'nin yedi farklı bölgesinde bulunan okul öncesi sınıf ortamlarının değerlendirilmesi bağlamında gönüllü olarak katılım gösteren 312 okul öncesi öğretmenine ulaşılmıştır. Çalışma grubuna ilişkin demografik bilgiler Tablo 1'de yer almaktadır. 
10 D.E., Çakar, K.Z., Deniz, N. Teke, T. Baş, E. Kılınçcı ve N, Aksoy/ Pamukkale Üniversitesi Eğitim Fakültesi Dergisi, 56, 1-34, 2022

Tablo 1. Çalışma Grubuna İlişkin Demografik Bilgiler (N=312)

\begin{tabular}{|c|c|c|c|}
\hline Değişkenler & Gruplar & $\mathbf{n}$ & $\%$ \\
\hline \multirow{2}{*}{ Cinsiyet } & Kadın & 300 & 96.2 \\
\hline & Erkek & 12 & 3.8 \\
\hline Toplam & & 312 & 100 \\
\hline \multirow{4}{*}{ Yaş } & $20-30$ yaş & 161 & 51.6 \\
\hline & $31-40$ yaş & 102 & 32.7 \\
\hline & 41 ve üzeri yaş & 40 & 12.8 \\
\hline & Cevap yok & 9 & 2.9 \\
\hline Toplam & & 312 & 100 \\
\hline \multirow{3}{*}{ Eğitim durumu } & Lise & 18 & 5.76 \\
\hline & Üniversite & 292 & 93.58 \\
\hline & Cevap yok & 2 & .06 \\
\hline Toplam & & 312 & 100 \\
\hline \multirow{3}{*}{ Kidem Y1lı } & 10 y1l ve 10 y1ldan az & 220 & 70.5 \\
\hline & 11 y1l ve üzeri & 72 & 23.1 \\
\hline & Cevap yok & 20 & 6.4 \\
\hline Toplam & & 312 & 100 \\
\hline \multirow{8}{*}{ Çalışılan Bölge } & Akdeniz Bölgesi & 18 & 5.77 \\
\hline & Karadeniz Bölgesi & 17 & 5.45 \\
\hline & İç Anadolu Bölgesi & 138 & 44.23 \\
\hline & Ege Bölgesi & 32 & 10.26 \\
\hline & Doğu Anadolu Bölgesi & 33 & 10.58 \\
\hline & Güneydoğu Anadolu Bölgesi & 48 & 15.39 \\
\hline & Marmara Bölgesi & 16 & 5.13 \\
\hline & Cevap yok & 9 & 2.89 \\
\hline Toplam & & 312 & 100 \\
\hline \multirow{3}{*}{$\begin{array}{l}\text { Çalışılan Kurumun Yerleşim } \\
\text { Yeri }\end{array}$} & Kent & 165 & 52.9 \\
\hline & Köy/Kasaba & 146 & 46.8 \\
\hline & Cevap yok & 1 & .3 \\
\hline Toplam & & 312 & 100 \\
\hline \multirow{2}{*}{ Çalışılan Kurumun Türü } & Resmi & 225 & 72.1 \\
\hline & Özel & 87 & 27.9 \\
\hline Toplam & & 312 & 100 \\
\hline
\end{tabular}

Tablo 1 incelendiğinde çalışma grubunun \% 96.2'sinin kadın, \% 3.8'inin erkek öğretmenlerden oluştuğu ve bu öğretmenlerin \% 51.6'sının 20-30 yaş, \%32.7'sinin 31-40 yaş aralığında ve \%12.8'sinin 41 yaş ve üzerinde olduğu görülmektedir. Öğretmenlerin \% 93.58'si üniversite, \%5.76'sının lise mezunu olduğu, \%70.5'i 10 yıl ve daha az ve \% 23.1'i 11 yıl ve daha fazla k1dem y1lına sahiptir. Öğretmenlerin \%44.23'ü İç Anadolu Bölgesi'nde, \%15.39'u Güneydoğu 
Anadolu Bölgesi'nde, \%10.58'i Doğu Anadolu Bölgesi'nde, \%10.26's1 Ege Bölgesi'nde, \%5.77'si Akdeniz Bölgesi'nde, \%5.45'i Karadeniz Bölgesi'nde ve \% 5.13'ü Marmara Bölgesi'nde yer alan okul öncesi eğitim kurumlarında çalışmaktadır. Öğretmenlerin çalıştıkları kurumun \%52.9'u kentte, \%46.8'i köy/kasabada yer almaktadır. Öğretmenlerin çalıştığ kurumların \% 72.1'i resmi, \%27.9'u özel okul öncesi eğitim kurumudur.

\section{Veri Toplama Aracını Geliştirme Basamakları}

Ölçme aracının geliştirilmesinde DeVellis (2017) tarafından belirtilen sekiz basamaktan yararlanılmıştır. Yapılan işlemler sırasıyla şu şekildedir:

1. Sınıf ortamı ile ilgili alan yazın taranmış, ilgili ölçme araçları ve okul öncesi sınıf ortamı kapsamında uluslararası program ve yaklaşımlar incelenmiştir.

2. Ölçme aracının ölçmeyi hedeflediği yapı doğrultusunda araştırmacılar beş farklı okul öncesi eğitim kurumuna giderek sınıf ortamlarına ilişkin gözlemler gerçekleştirmiştir. Sonrasında alan yazından elde edilen bilgiler ve gözlemler doğrultusunda bir madde havuzu hazırlanmıştır. Ölçek maddeleri geliştirilirken MEB Okul Öncesi Eğitim Programı, High-Scope Yaklaşımı, Sosyo-Kültürel Gelişim Kuramı, Sosyal Öğrenme Kuramı ve Ekolojik Sistemler Kuramı temel alınmıştır.

3. Ölçme aracı öğretmenlerin kendi sınıf ortamlarını değerlendirmesine yönelik 5'li Likert tipi ölçeklendirilmiştir ve hiçbir zaman (1), nadiren (2), ara sira (3), genellikle (4), her zaman (5) olarak derecelendirilmiştir.

4. Maddeler uzman görüşlerine sunulmuştur. $\mathrm{Bu}$ aşamada bir okul öncesi öğretmeni, okul öncesi eğitim alanında doktora derecesi almış ve okul öncesinde sınıf ortamlarına ilişkin çalışmaları bulunan bir öğretim elemanı ve ölçme ve değerlendirme alanında doktora derecesini almış bir öğretim elemanından uzman görüşü alınmıştır.

5. Uzmanların verdiği geribildirimler doğrultusunda ölçme aracında düzenlemeler yapılmış ve 64 maddelik taslak form oluşturulmuştur.

6. Okul öncesi öğretmenlerinden 103 katılımcıya kendi sınıf ortamlarını bu taslak form ile değerlendirmeleri istenerek pilot uygulama gerçekleştirilmiştir. Pilot uygulama ile ölçme aracındaki maddelerin okunabilirliği, anlaşılır olması, yanıtlayıcılar tarafından anlaşılmayan yerlerin belirlenmesi, yazım hatalarının tespit edilmesi, ortalama yanıtlama süresinin belirlenmesi açısından uygunluğunun tespit edilmiştir. $\mathrm{Bu}$ doğrultuda ölçme aracındaki 
12 D.E., Çakar, K.Z., Deniz, N. Teke, T. Baş, E. Kılınçcı ve N, Aksoy/ Pamukkale Üniversitesi Eğitim Fakültesi Dergisi, 56, 1-34, 2022 maddelere ilişkin uygun düzeltmeler yapılarak ölçeğe iki maddelik Erken Çocukluk Sınıf Ortamı Değerlendirme Ölçeği (EÇSODÖ) 66 maddelik deneme formu oluşturulmuştur.

7. Deneme uygulaması toplam 312 okul öncesi öğretmeni ile gerçekleştirilmiştir. Ölçeğin geçerlik çalışmalarında; kapsam geçerliği için uzman görüşleri alınmıştır. Yapı geçerliği için Temel Bileşenler Analizi 194 okul öncesi öğretmeninden ve DFA 118 okul öncesi öğretmeninden alınan veriler ile gerçekleştirilmiştir. Ölçeğin güvenirlik çalışmalarında; Cronbach alfa iç tutarlılık katsayıları belirlenmiştir.

8. Analiz sonuçları bulgular bölümünde detaylı olarak ele alınmıştır.

\section{İșlem}

Verilerin toplanması amacıyla öncelikle Ankara Üniversitesi Sosyal Bilimler Alt Etik Kurulu'ndan çalışmanın etik ilkelere uygunluğu açısından onay alındıktan sonra Milli Eğitim Bakanlığı'ndan gerekli izinler alınmıştır. Verilerin toplanması amacıyla Türkiye'deki bütün illerde anaokullarında görev yapan okul öncesi öğretmenlerine geliştirilen ölçek kâğıda basılmış şekliyle ulaştırılmaya çalışılmıştır. Araştırmacılar tarafından ulaşılamayan illerde ise, okul öncesi öğretmenlerine ölçeğin çevrimiçi hali ulaştırılmıştır. Veri toplama sürecinde Türkiye'de yedi bölgede bulunan (Akdeniz Bölgesi, Karadeniz Bölgesi, Ege Bölgesi, Marmara Bölgesi, İç Anadolu Bölgesi, Doğu Anadolu Bölgesi, Güneydoğu Anadolu Bölgesi) 81 ilin 43 iline ulaşılmıştır. Öğretmenler, kendi sınıf ortamlarını, ölçek maddeleri doğrultusunda değerlendirmişlerdir. Öğretmenlere ölçme aracının nasıl kullanılacağı eğitimler aracılığıyla örneklerle anlatılmıştır. Açıklamalar ve ölçme aracı incelendikten sonra öğretmenlerden kendi sınıf ortamlarını değerlendirmeleri istenmiştir.

\section{Veri Analizi}

Okul öncesi öğretmenleri Erken Çocukluk Sınıf Ortamı Değerlendirme Ölçeği’ni (EÇSODÖ) kullanarak kendi sınıflarında çocuklara sağladıkları sınıf ortamlarını değerlendirdikten sonra veriler bilgisayar ortamına aktarılarak analizler yapılmıştır. Erken Çocukluk Sınıf Ortamı Değerlendirme Ölçeği (EÇSODÖ) için öncelikle TBA daha sonra DFA yapılmıştır. Faktör analizi, kuram geliştirme ya da test etmede ve altta yatan yapıyı anlamak için kullanılmaktadır (Tabachnick ve Fidell, 2015). Temel faktör çıkarma prosedürünün temel özelliği her faktörün, çarpanlara ayrılan değişkenlerin varyansının mümkün olan maksimum miktarını hesaba katmasıdır (Gorsuch, 1974). Dolayısıyla en az değişkenle en çok varyans açıklama amacıyla TBA kullanılmıştır. Ölçeğin maddeleri arasında iç tutarlık güvenirliği Cronbach alfa iç tutarlılık güvenirliği hesaplanmıştır. 


\section{Bulgular}

Ölçek maddeleri M1- M66 aralığında numaralandırılmıştır. Ölçeğin veri setinde kayıp veri olmadığı belirlenmiş ve ölçeğin (66 maddelik) yapı geçerliğini belirlemek amacıyla keşfedici çalışmalardan Temel Bileşenler Analizi yapılmıştır. Bu analizde hesaplanan Kaiser Mayer Olkin (KMO) katsayısı 1'e yaklaştıkça verilerin analize uygun olduğu, 1 olması ise mükemmel uyum anlamına gelir (Kalaycı, 2006). KMO'nun .60'dan yüksek ve Barlett Sphericity testinin anlamlı çıkması verilerin faktör analizi için uygun olduğunu göstermektedir (Büyüköztürk, 2020). Erkuş (2019), faktör analizinde örneklem büyüklüğü konusunda değişken sayısına göre, faktör sayısına göre vb. çeşitli görüşler olduğunu ancak üzerinde kesin uzlaşılan bir sayı veya oran olmadığını vurgulamaktadır.

Verilerin TBA'ya uygunluğu incelendiğinde KMO değerinin .80'den yüksek olduğu $(\mathrm{KMO}=.85)$ için örneklem sayısının yeterli olduğu ve Bartlett testi sonuçlarının $\left(\mathrm{X}^{2}=3469.901\right.$, $\mathrm{df}=703, \mathrm{p}<0.05)$ anlamlı olduğu bu durumda ise normal dağglım sağlandı̆̆ TBA'ya uygun olduğu değerlendirilmiştir. Determinant katsayısının ise, .00001'den büyük olduğu (.009) belirlenmiş ve çoklu bağlantılılık sorunu bulunmadığına karar verilmiştir.

Ölçeğin kaç faktörlü bir yapısı olduğuna karar vermek için Horn’un (1965) Paralel Analizi'nden yararlanılmıştır. SPSS ve Paralel analiz çıktıları karşılaştırıldığında altıncı faktöre kadar SPSS’teki faktör öz değerlerinin Paralel Analiz'deki öz değerlerden yüksek olduğu ve altıncı faktörün Paralel Analiz'deki öz değerinin ise SPSS'deki öz değerden daha büyük olduğu anlaşılmış ve karşılaştırma beşinci faktörde kesilmiştir. Bunun sonucunda ölçeğin beş faktörlü bir yapıya sahip olduğu anlaşılmıştır.

Dik döndürme tekniklerinden varimax dik döndürme tekniği kullanılmıştır. Ho (2006)'ya göre faktörler arasındaki ilişki düşük olduğunda (faktörler bağımsız olduğunda) dik döndürme tekniği kullanılmaktadır. Faktörler arasındaki ilişkilerin düşük olacağı öngörülmüş ve analiz sonucunda da beş faktörün birbirleri arasındaki ilişki düzeyleri bu durumu doğrulamıştır (korelasyon değerleri -0,376 ile 0,202 arasındadır.) Büyüköztürk (2020) de faktörlerin daha belirgin olması için dik döndürme önermektedir. Rotasyonun amacı, yorumlanabilir, anlamlı faktörler elde etmektir (Tabachnick ve Fidell, 2015). Rotasyon sonucunda madde öz değerleri .30'dan düşük olan ve binişiklik gösteren maddeler (M1, M2, M3, M4, M5, M6, M7, M8, M15, M18, M26, M28, M30, M31, M32, M33, M34, M35, M36, M37, M38, M47, M54, M58, M63, M64, M65, M66) analiz dışı bırakılmıştır. 
14 D.E., Çakar, K.Z., Deniz, N. Teke, T. Baş, E. Kılınçcı ve N, Aksoy/ Pamukkale Üniversitesi Eğitim Fakültesi Dergisi, 56, 1-34, 2022

Ölçeğin kaç faktörlü yapısı olduğuna karar vermek için faktörlerin öz değerlerine bakılmış ve özdeğeri 1'den büyük faktörler Tablo 2'de verilmiştir.

Tablo 2. Özdĕger Istatistiğine Bă̆ll Faktör ve Açıklanan Varyans Yüzdesi

\begin{tabular}{llll}
\hline \multirow{2}{*}{ Bileşenler } & \multicolumn{2}{l}{ Başlangıç Öz Değerleri } \\
\cline { 2 - 4 } & Toplam & $\begin{array}{l}\text { Açılanan } \\
\text { Varyans }\end{array}$ & $\begin{array}{l}\text { Toplam Açıklanan } \\
\text { Varyans } \\
\text { \% }\end{array}$ \\
\hline 1 & & 25.707 & 25.707 \\
2 & 9.769 & 9.406 & 35.113 \\
3 & 3.574 & 7.050 & 42.162 \\
4 & 2.679 & 5.775 & 47.937 \\
5 & 2.194 & 4.191 & 52.128 \\
7 & 1.593 & 3.053 & 55.181 \\
8 & 1.160 & 2.874 & 58.055 \\
\hline
\end{tabular}

Tablo 2 incelendiğinde ölçeğin öz değeri 1'den daha büyük sekiz faktöre sahip olmas1, ölçeğin sekiz faktörden oluşabileceğini göstermektedir. Ancak beş faktörden sonra keskin bir düşüş olmadığı için beş faktörlü bir ölçek olabileceği düşünülmüştür.

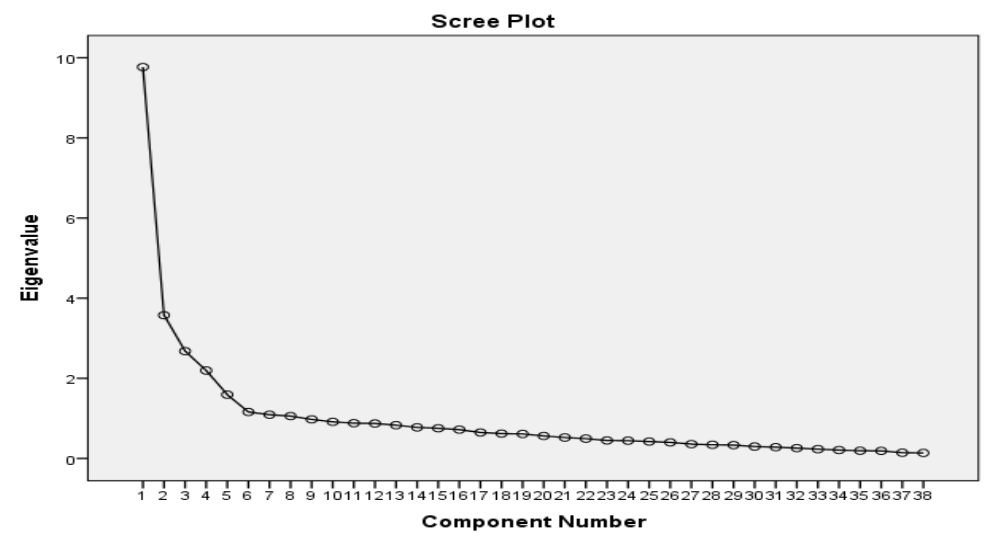

Şekil 1. Faktör Analizi Özdĕ̌ger Grafiği

Şekil 1 incelendiğinde özdeğer grafiğinde özdeğeri 1'den büyük sekiz farklı noktada kırılma/bükülme görülmüştür. Ancak grafikte beş faktörden sonra keskin bir düşüş olmadığından ölçeğin beş faktörlü olabileceği düşünülmüştür.

Madde öz değerleri ve maddelerin rotasyon sonucunda belirlenen faktör yükleri Tablo 3'te verilmiştir. 
Tablo 3. Maddelerin Öz Değerleri, Rotasyon Sonrası Faktör Yükleri ve Açıklanan Varyans Düzeyi

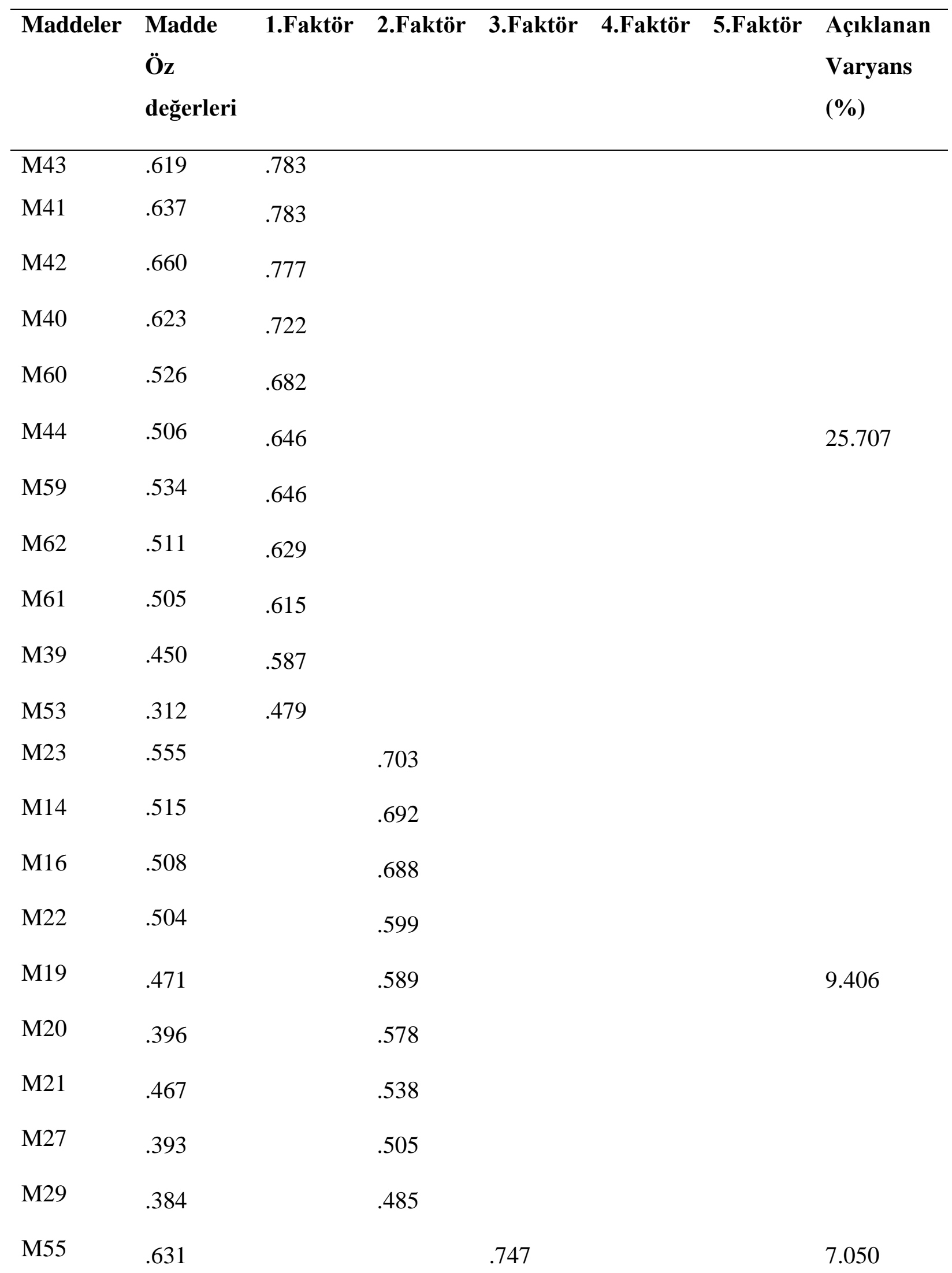


16 D.E., Çakar, K.Z., Deniz, N. Teke, T. Baş, E. Kılınçcı ve N, Aksoy/ Pamukkale Üniversitesi Eğitim Fakültesi Dergisi, 56, 1-34, 2022

M56 .600

.720

M45 .549 .718

M46 .527 .701

M25 .437

.394 .647

M10

.603 .562
.755

.744

.687

.633

.539

.538

.722

.689

.668

4.191

.631

.453

5.775

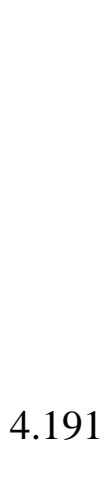

.505

.434

.669

M50

.626 .390

M52

M48

Tablo 3 incelendiğinde maddelerin öz değerlerinin .312-.660 aralığında olduğu bu durumda maddelerin öz değerleri .30 'dan kü̧̧ük olduğu için çıkarılacak madde bulunmamaktadır. 1. Faktörde 11 maddenin (M43, M41, M42, M40, M60, M44, M59, M62, M61, M39, M53) yer aldığı ve maddelerin faktör yüklerinin .479-.783 aralı̆ıında olduğu, 2. Faktörde dokuz maddenin (M23, M14, M16, M22, M19, M20, M21, M27, M29) yer aldığ ve maddelerin faktör yüklerinin .485-.703 aralığında olduğu, 3. Faktörde yedi maddenin (M55, M56, M45, M46, M25, M24, M57) yer aldığı ve maddelerin faktör yüklerinin .562-.747 aralığında olduğu, 4. Faktörde altı maddenin (M10, M12, M9, M11, M17, M13) yer aldığ ve maddelerin faktör yüklerinin .538-.755 aralı̆̆ında olduğu, 5. Faktörde beş maddenin (M50, M49, M51, M52, M48) yer aldığı ve maddelerin faktör yüklerinin .538-.755 aralığında olduğu, görülmüştür. Ölçeğin 38 maddeden oluştuğu ve 1.faktörün toplam varyansın \%25.71'ini, 
2.faktörün \%9.41'ini, 3.faktörün \% 7.05'ini, 4.faktörün \%5.76'sın1, 5.faktörün ise \%4.19'unu açıkladığı ve toplamda \%52.13 oranında ortak varyansın açıklandığı belirlenmiştir.

Çocuğun problemi fark etmesini, soru sorarak çözüm üretmesini, üretilen çözümlerin tartışılmasını, ortak çözüm yoluna karar verilmesini desteklemeyi içeren maddelerden oluşan 1. Faktör "Problem çözmenin desteklenmesi" şeklinde isimlendirilmiştir. Bu faktör altında yer alan maddelerden ikisine örnek olarak aşağıda yer verilmiştir.

M39. Çocuğun problemi fark etmesini sağlarım (Örneğin, oyuncak paylaşımı konusunda sorun yaşayan iki çocuğa “Sizce buradaki sorun ne? ”, Yaşadığınız problemi anlatabilir misiniz?' gibi sorular sorarak çocukların problemi fark etmesini sağlama).

M53. Sinıf ile ilgili kararların alınması sürecine çocukları dâhil ederim (Örneğin, ögrenme merkezlerinin düzenlenmesi veya merkezlerde çalışacak öğrenci sayısının belirlenmesi gibi sınıf kurallarının oluşturulması durumlarında çocuklarla birlikte ortak kararlar alınmasını sağlama).

Çocuklara sınıf kuralları ve rutinlerine yönelik olarak beden dili, materyal kullanarak ya da sözlü olarak geri bildirim vermeyi içeren ve örnek olarak ikisine aşağıda yer verilen maddelerden oluşan 2. Faktör "Etkili geri bildirim verilmesi" şeklinde isimlendirilmiştir.

M14. Sınıf kurallarını sözel ifadeler kullanarak hatırlatırım (Örneğin, sınıfta koşan bir çocuğa “sınıfta yürüyerek hareket ediyoruz” diyerek sınıf kuralını hatırlatma).

M23. Olumsuz davranışa dönük sözel geri bildirim veririm (Örneğin, "Kızgınsan, arkadaşını itmek yerine bu yaptığından hoşlanmıyorum diyebilirsin" vb. ifadeler kullanma).

3. Faktör altında, çocukların bireysel farklılıklarına ve gelişim düzeylerine bakılmaksızın öğretmenin çocukların davranışlarına yönelik olumsuz ifadelerini içeren maddeler ters kodlanmış ve "Olumlu davranışların teşvik edilmesi” olarak isimlendirilmiştir. $\mathrm{Bu}$ faktör altında yer alan maddelere örnek olarak aşağıdakiler verilmiştir.

M55. Cinsiyete yönelik sözel ifadeler kullanırım (Örneğin, erkek çocuğa "Erkek adam ă̆lamaz”, "Sen erkeksin oyuncak bebeklerle oynama”, kız çocuğa "Sen kızsın tamir aletleriyle oynama" gibi ifadeler kullanma).

M57. Toplumsal cinsiyet rollerine yönelik materyaller bulundururum (Örneğin, anneleri ev işi yaparken babaları tamir işleri ile uğraşırken gösteren afiş, kitap, oyuncak vb. materyalleri bulundurma veya kullanma). 
18 D.E., Çakar, K.Z., Deniz, N. Teke, T. Baş, E. Kılınçcı ve N, Aksoy/ Pamukkale Üniversitesi Eğitim Fakültesi Dergisi, 56, 1-34, 2022

Çocuklar için uygun fiziksel sınıf ortamı ve materyalleri hazırlamayı içeren maddelerden oluşan 4. Faktör "Nitelikli fiziksel sınıf ortamı" olarak isimlendirilmiştir. Bu faktöre ait örnek maddeler şunlardır:

M9. Öğrenme merkezlerinde yeterli sayıda materyal bulundururum (Örneğin, aynı anda birkaç çocuğun birlikte oynayabilmelerine olanak tanıyan, yeterli sayıda materyal bulundurma).

M17. Günlük akış sıralamasını hatırlatıcı işaretler kullanırım (Örneğin, çocuklarla birlikte günlük eğitim aklşını inceleyerek, olay örgüsü kartlarını kullanarak vb. şekilde çocukların bir sonraki adımı takip etmelerini să̆lama).

Çocukların bağımsız davranmasını, bireysel girişimlerini, liderlik davranışlarını ve başarılı olacağına inanma duygusunu desteklemeyi içeren maddelerden oluşan 5. Faktör “Özyeterliğin desteklenmesi” şeklinde isimlendirilmiştir. Bu faktöre ait örnek olarak aşağıdaki maddelere yer verilmiştir.

M51. Çocuğun topluluk önünde konuşmasını/kendini ifade etmesini desteklerim

(Örneğin, hikâye anlatma, yapmış olduğu ürünleri sözlü olarak sunma, bir konu hakkında duygu ve düşüncelerini ifade etme, bir materyali tanıtma gibi uygulamalarla destekleme).

M52. Çocuğun başarma duygusunu hissetmesini sağlarım (Örneğin, çocuğa, gelişim düzeyine uygun roller ve sorumluluklar vererek çocuğun başarılı olmasını sağlama).

Ölçeğin TBA sonucunda belirlenen 38 madde 5 faktörden oluşan yapısını test etmek için gerçekleştirilen DFA sonucunda gözlenen değişkenlerin gizil değişkenleri açıklama oranlarına ilişkin t değerleri Şekil 2'de yer verilmiştir. 


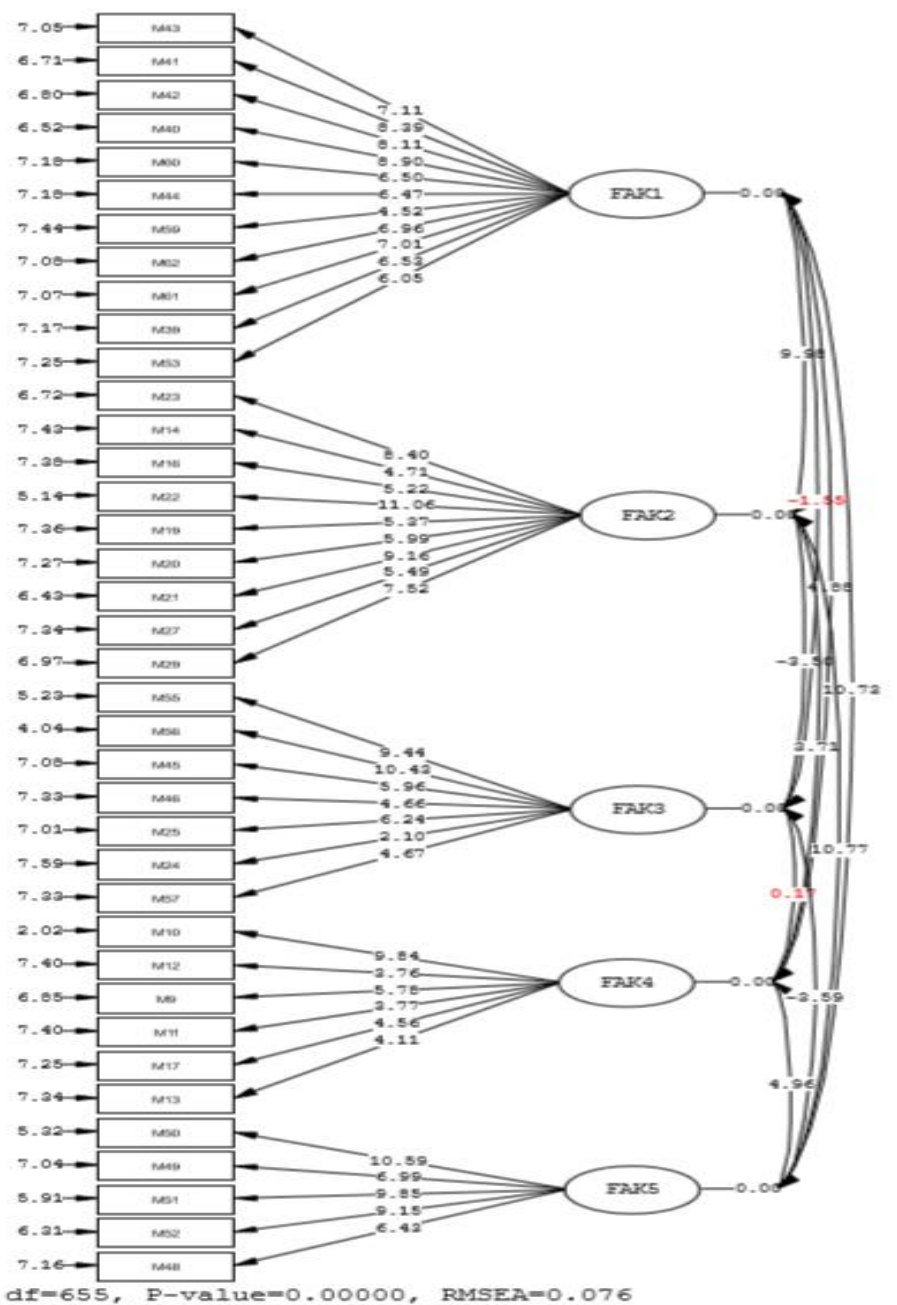

Şekil 2. Gizil ve Gözlenen Değişkenler Arasındaki Illişkiye Yönelik t Değerleri

Şekil 2 incelendiğinde ölçeğin beş faktörlü yapısına ilişkin modeldeki değişkenler arasındaki ilişkilerin $\mathrm{t}$ değerleri görülmektedir. $\mathrm{t}$ değerlerinin 1.96'dan yüksek olması .05 düzeyinde anlamlı olduğunu göstermektedir. Modelde anlamlı olmayan değerlerin analize dahil edilmemesi gerekmektedir (Çokluk, Şekercioğlu ve Büyüköztürk, 2014). Bu modeldeki t değerlerinin 2.10-11.06 arasında ve .05 düzeyinde anlamlı olduğu için analiz dışında bırakılacak herhangi bir madde olmadığına karar verilmiştir.

Modeldeki değişkenlerin arasındaki ilişkilere yönelik standartlaştırılmış katsayılar ve maddelerin hata varyansları Şekil 3'te verilmiştir. 


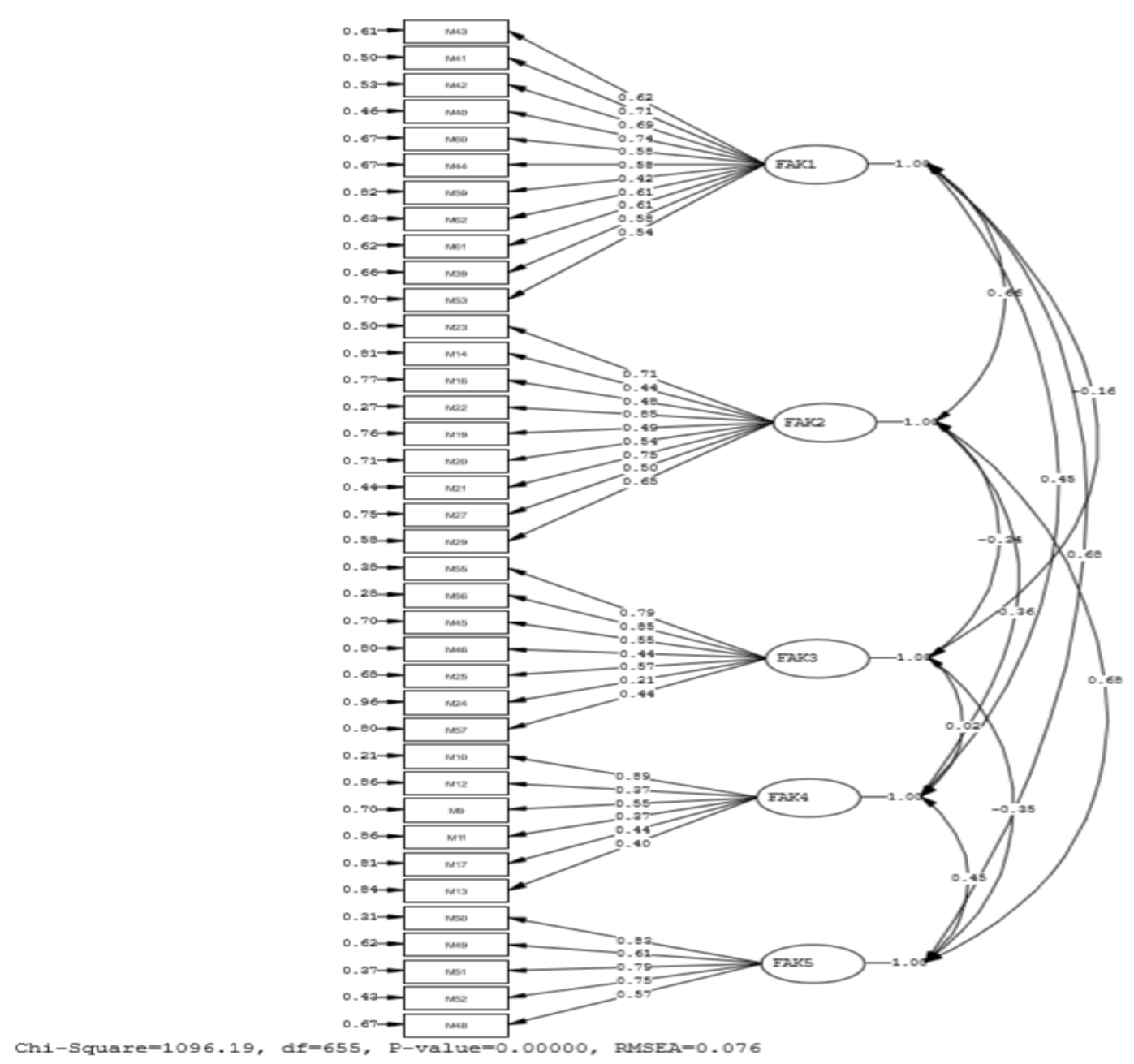

Şekil 3. Gizil ve Gözlenen Değişkenler Arasındaki İlişkiye Yönelik Standartlaştırılmış

\section{Katsayılar}

Şekil 3 incelendiğinde, 1. faktör ve maddeleri arasında .42-.74, 2. faktör ve maddeleri arasında .44-.85, 3.faktör ve maddeleri arasında .21-.85, 4. faktör ve maddeleri arasında .37.89 , 5. faktör ve maddeleri arasında $.57-.83$ aralığında değişen ilişkilerin olduğu belirlenmiştir.

Analizler sonucunda $\chi 2=1096.19, \mathrm{sd}=655$ olarak bulunmuştur. $\chi 2 /$ sd değerinin üçün altında olması mükemmel uyumu ifade etmektedir (Kline, 2005). $\chi 2 /$ sd $(1096.19 / 655)$ değerinin 1.67 olduğu görülmektedir, bu da modelin mükemmel uyumu sağladığını göstermektedir. DFA sonucuna ilişkin uyum iyiliği değerleri Tablo 4'te yer almaktadır.

Tablo 4. DFA Sonucuna İlişkin Uyum İyiliği Değerleri

\begin{tabular}{lccccccc}
\hline RMSEA & RMR & AGFI & GFI & NNFI & NFI & IFI & CFI \\
\hline .076 & .059 & .63 & .67 & .89 & .79 & .90 & .90 \\
\hline
\end{tabular}

Tablo 4 incelendiğinde RMSEA (.076) ve S-RMR (.025) uyum indekslerinin .05 altında olması nedeniyle mükemmel uyumu sağladığı görülmüştür (Jöroskog ve Sörbom,1993). 
Tablo 4 incelendiğinde GFI, AGFI, NFI, NNFI, CFI, IFI uyum indeksleri incelendiğinde $\mathrm{AGFI}=.63, \mathrm{GFI}=.67, \mathrm{NNFI}=.89, \mathrm{NFI}=.79, \mathrm{IFI}=.90, \mathrm{CFI}=.90$, olduğu görülmektedir. $\mathrm{Bu}$ durumda GFI, AGFI, NFI değerlerinin .90'dan küçük olması nedeniyle zayıf uyuma, NNFI, CFI, IFI' nın .90 olmaları nedeniyle iyi uyumu sağladığı görülmüştür (Tabachnick ve Fidell, 2015).

Ölçeğin güvenirliği için hesaplanan Cronbach alfa iç tutarlık katsayısı 1. Faktör (Problem çözmenin desteklenmesi) için .86, 2. Faktör (Etkili geri bildirim verilmesi) için .84, 3. Faktör (Olumlu davranışların teşvik edilmesi) için .74, 4. Faktör (Nitelikli fiziksel sınıf ortamı) için .66 ve 5. Faktör (Özyeterliği destekleme) için .84 olarak belirlenmiştir. Değerler incelendiğinde 4. Faktör Cronbach alfa katsayısının beklenen alt sınır olan .70 'in biraz altında olduğu görülmüştür. Faktör yük değerlerinin de yüksek olduğu bu faktörün madde sayısı ileriki çalışmalarda artırılarak daha güçlü hale getirilebilir. Bu doğrultuda ölçeğin güvenilir bir araç olduğuna karar verilmiştir (Kayış, 2016; Pallant, 2017). Analizler sonrasında geçerli ve güvenilir, alt boyut puanları üzerinden analizlerin gerçekleştirilebileceği bir ölçek elde edilmiştir.

\section{Tartışma}

Sınıf ortamlarını değerlendirmenin en etkili ve güvenli yollarından biri standardize edilmiş araçlardır (Hui, Lee ve diğerleri, 2017). Bu doğrultuda, yapılan bu çalışmada erken çocukluk sınıf ortamlarının özelliklerini değerlendirmek için bir ölçme aracının geliştirilmesi amaçlanmıştır. Bu amaç doğrultusunda 66 maddelik bir deneme formu hazırlanmış ve formun uygulaması 312 okul öncesi öğretmeni ile gerçekleştirilmiştir. Ölçeğin geçerlik çalışmalarında; kapsam geçerliği için uzman görüşleri alınmış, yapı geçerliği için TBA ve DFA yapılmış; güvenirlik analizleri kapsamında ise iç tutarlılık katsayıları belirlenmiştir. Yapılan tüm analizler sonucunda 5 faktör ve 38 maddeden oluşan geçerli ve güvenilir bir ölçme aracı elde edilmiştir. Oluşturulan ölçme aracının özellikle Türk kültürü ve Türkiye'deki okul öncesi eğitim programı ile uyumlu olmasından kaynaklı olarak literatüre katkı getireceği ve sınıf ortamının hem fiziksel hem sosyal ortam açısından değerlendirilmesinin, ortamların güçlü ve zayıf yönlerini belirlemesi ve yapılacak düzenlemelerin önünü açmasından kaynaklı olarak alana fayda sağlayacağı düşünülmektedir.

Geliştirilen ölçeğin faktör yapıları Problem çözmenin desteklenmesi, etkili geri bildirim verilmesi, olumlu davranışların teşvik edilmesi, nitelikli fiziksel sınıf ortamı ve özyeterliğin desteklenmesi olmak üzere beş başlıktan oluşmaktadır. Bu faktörler ve faktörlerin altında yer 
22 D.E., Çakar, K.Z., Deniz, N. Teke, T. Baş, E. Kılınçcı ve N, Aksoy/ Pamukkale Üniversitesi Eğitim Fakültesi Dergisi, 56, 1-34, 2022 alan maddeler sınıf ortamlarının değerlendirilmesi için daha önce oluşturulmuş ölçme araçlarında bulunan faktörler ve maddeler ile paralellik göstermekte ve bu durum da ölçeğin geçerliliğini ortaya koymaktadır. Alan yazında kullanılan ölçme araçlarında (Fish ve Dane, 2000; Harms, Clifford ve Cryer, 2005; Kragh-Müller ve Ringsmose, 2015; Maxwell, 2007; Pianta, La Paro ve Hamre, 2008) benzer faktör yapıları farklı isimlendirilmiş ya da benzer maddeler farklı faktörler altında gruplanmış olsa dahi sınıf ortamını değerlendirmek için öne sürülen kriterler ortaktır. $\mathrm{Bu}$ araştırmada geliştirilen ölçme aracındaki 'Problem çözmenin desteklenmesi’ faktörü altında problem çözme sürecinde akran yardımının desteklenmesi, sınıf ile ilgili kararların alınması sürecine çocukların dâhil edilmesi ve farklı fikirlere saygı duyulan bir ortam sağlanması gibi maddeler Fish ve Dane'nin (2000) oluşturdukları sınıf ortamı değerlendirme ölçeğinde classroom cohesion, classroom flexibility ve classroom communication faktörleri altında akranların sınıf içinde birbirlerine yardımcı olmaları, kararların öğretmen-çocuk işbirliği içinde alınması ve çocukların özgürce kendilerini ifade etmeleri gibi maddeler ile değerlendirilmektedir. Çocukların kendilerini ifade etmeleri için firsat verilmesi ve farklı fikirlere saygı duyulan bir ortam sağlanması; cesaret verici, açık ve kabul edici özellikleri olan yüksek kaliteli bir psycho-social environment örneğidir (HavuNuutinen ve Niikko, 2014). Yine bu faktör altında incelenen çocuğun bir etkinliği/performansı sergilemesi için gerekli görevleri organize etmesini destekleme durumu, çocuğun aktif öğrenmesi ve keşif ve düzenleme becerileri için önemli olduğundan bir öğrenme ortamının birincil amaçlarındandır (Vosniadou, Ioannides, Dimitrakopoulou ve Papademetriou, 2001). Diğer taraftan, Ocak (2010) çocukların farklı alanlarda birçok farklı çözüm yolu ile ilgili düşünme becerisine sahip olmaları için öğretmenlerin eğitim ve modelleme yoluyla çocuklara bu tür bir perspektife sahip olmaları için rehberlik etmeleri ve destek vermeleri gerektiğini belirtmektedir. Solak (2007) tarafından Türk kültürüne uyarlaması yapılan bir ölçme aracında çocukların kendi problemlerini çözmeleri için öğretmen desteğinin sağlanması bir madde olarak disiplin kategorisi altında incelenmektedir. Geliştirilen ölçme aracında da Problem çözmenin desteklenmesi faktörü altında çocukların problemi fark etmesini sağlama, soru sorarak, ipucu vererek, çözüm önerilerini tartışarak ve uygulayarak problemi çözmeye çalışma gibi destek olma stratejileri ele alınmaktadır.

'Etkili geri bildirim verilmesi' faktörü bu çalışmada olduğu gibi birçok farklı ölçme aracında da faktör yapısı ya da farklı faktör yapıları altında bir madde olarak incelenmiştir. Örneğin, Reddy, Fabiano ve Dudek (2013) tarafından geliştirilen bir ölçme aracında faktör olarak ele alınmış ve öğretmenin olumlu veya olumsuz davranışlar için sözlü veya sözsüz bir 
ifade veya jest ve mimikleri kullanarak geri bildirim verme durumları ve bu sayede çocukların fikirlerine, yorumlarına ve çalışmalarına verdikleri yanıtlarla çocukların öğrenmelerini nasıl destekledikleri incelenmiştir. Bir diğer çalışmada, Hancock ve Carter (2016) de oluşturdukları ölçme aracında uygun davranışı onaylama ve sorunlu davranışa tutarlı bir şekilde cevap verme faktörü altında geri bildirim verme durumuna değinmiştir. Yapılan bu çalışmada etkili geri bildirim verilmesi; olumlu ve olumsuz davranışlara yönelik sözel geri bildirim verilmesi, beden dilini ve fiziksel teması kullanarak geri bildirim verilmesi veya çocukların duygularını ifade edici geri bildirim verilmesi gibi maddeler ile ayrıntılı olarak ele alınmıştır.

'Olumlu davranışların teşvik edilmesi' faktörü altında incelenen çocuğun gelişiminin üstünde veya altında etkinlik vermeme ile çocuklar arası rekabeti destekleyecek geri bildirim vermeme durumları, Fraser ve Fisher (1982) tarafından geliştirilen Benim Sınıfım Envanteri (My Class Inventory)' de çocuklara verilen görevlerin kolaylık-zorluk seviyesi ve sınıf içindeki rekabet ortamı şeklinde birer faktör olarak ele alınmıştır. Çocuklara kendi seviyelerine uygun olarak deneyimler sunulması, yeteneklerini fark etmelerini ve yetersizlik duygusu içinde kaybolmamalarını da sağlamaktadır (Bandura, 1989). Diğer taraftan çocukları kıyaslamaktan kaçınmak işbirliğini desteklemesi için önemli olmakla beraber (Senemoğlu, 2015) etkili bir sınıf ortamının sağlanması için dikkat edilmesi gereken bileşenlerden bir tanesidir. Ek olarak, bu faktör yapısı altında yer alan çocukların cinsiyetlerine göre öğretmenin sözel ifadelerini, etkinlikleri veya materyalleri belirlememesi durumu diğer ölçme araçlarında yeterince dikkate alınmasa da bu uygulamaların çocuklarda yanlış cinsiyet kalıpları ve toplumsal cinsiyet normları oluşturduğu (Aina ve Cameron, 2011) ve hatta çocukların sahip olduğu ilgi ve becerileri şekillendirdiği (Wolter, Braun ve Hannover, 2015) bilindiğinden bu ölçme aracında incelenmiş ve etkili sınıf ortamını oluşturulan faktörlerden biri olarak ele alınmıştır.

Yapılan bu çalışmada 'nitelikli fiziksel sınıf ortamı' faktörlerden bir tanesidir ve daha önce geliştirilen ölçme araçları ile paralellik gösteren birçok maddeden oluşmaktadır. Örneğin, bu ölçekte bulunan yeterli sayıda ve farklı oyun deneyimlerini destekleyecek çeşitlilikte ve aile yaşantılarını yansıtacak şekilde materyal bulundurulması durumu, Hyson, Hirsh-Pasek ve Rescorla (1990) tarafından geliştirilen ölçme aracında (Classroom Practices Inventory) öğretmenin sınıfta dramatik oyun, blok, bilim, matematik, kitap, sanat ve müzik gibi öğrenme merkezlerini oluşturması ve bu merkezlerde yeterince çeşitlilikte ve çocukların günlük yaşam deneyimlerini destekleyici materyaller bulundurması olarak ele alınmıştır. Çocukların aile yaşantılarını bir diğer deyişle çocukların kendi kültürlerini yansıtacak materyaller bulundurulması Siwatu, Putman, Starker-Glass ve Lewis (2015) tarafından geliştirilen bir 
24 D.E., Çakar, K.Z., Deniz, N. Teke, T. Baş, E. Kılınçcı ve N, Aksoy/ Pamukkale Üniversitesi Eğitim Fakültesi Dergisi, 56, 1-34, 2022 ölçme aracında çocukların kültürlerini bilme ve saygı duyma, çocukların kültürlerini sınıfa taşıma ve etkili bir sınıf ortamı hazırlamada kullanma gibi birçok madde ile ayrıntılı olarak incelenmiştir. Yine bu faktör altında bulunan sınıf kurallarını materyaller kullanarak hatırlatma ve günlük akış sıralamasını hatırlatıcı işaretler kullanma, Hancock ve Carter (2016) tarafından geliştirilen ölçme aracında olumlu davranışı desteklemek için öngörülebilir, düzenli bir sınıf ortamı oluşturma faktörü altında bulunmaktadır. Diğer taraftan, Havu-Nuutinen ve Niikko (2014)'nun okul öncesi öğrenme ortamının üç boyutundan biri olarak ifade ettiği fiziksel-estetik ortam boyutu doğal malzemeler ile inşa edilmiş bir ortamı işaret etmekte ve bu kriter geliştirilen bu ölçekte de bir madde olarak yer almaktadır. Bir diğer deyişle, bu faktör altında bulunan maddeler ayrı ayrı birçok ölçme aracında benzer veya farklı faktör yapıları altında toplanmış olarak yer almakta ve sınıf ortamını değerlendirme noktasında çoğu ölçme aracında önemli görülmek ile beraber fiziksel ortamı tanımlamada kullanılmaktadır.

Kragh-Müller ve Ringsmose'a göre (2015) bir sınıf ortamının kalitesini belirleyen faktörlerden biri ortamda çocukların özgüveninin ve sosyal yetkinliğinin desteklenmiş olmasıdır. Bu durum geliştirilen ölçeğin son faktörü olan ‘özyeterliğin desteklenmesi’ faktörü altında ele alınmakta ve öğretmenin çocuğun liderlik becerilerini desteklemesi ve başarma duygusunu tatması için uygun ortamı oluşturması beklenmektedir. Ayrıca, bu faktör altında çocukların kendi aktivitelerini özgürce seçebilme, bağımsız davranabilme ve bireysel çalışmalarda bulunabilme gibi maddeler de bulunmakta ve bu maddeler Hyson, Hirsh-Pasek ve Rescorla (1990) tarafından erken çocukluk sınıf ortamını değerlendirmek için geliştirilen bir ölçme aracında da birer madde olarak değerlendirilmektedir. Diğer taraftan çocuğun topluluk önünde konuşmasını ve kendisini ifade etmesini destekleme durumu, Phillips, Zhao ve Weekley (2018) tarafından geliştirilen ölçme aracında çocukların konuşmaları için teşvik edilmesi olarak ele alınmakta ve bu durum da dil becerilerinin gelişmesi için önemli olarak görülmektedir. Genel olarak ‘özyeterliğin desteklenmesi’ faktörü veya faktör altında bulunan maddeler sınıf ortamını değerlendirme konusunda ortak bir kriter olarak kabul edilmektedir.

Erken Çocukluk Sınıf Ortamı Değerlendirme Ölçeği'nin (EÇSODÖ) güvenirlik çalışmaları kapsamında ise faktörlerin iç tutarlılık katsayıları hesaplanmış ve analiz sonuçlarına göre her maddenin yer aldığı faktöre uyum sağladığı ve maddelerin birbirleri ile tutarlılık gösterdiği bulunmuştur (Pallant, 2017). Bu durum da oluşturulan ölçeğin erken çocukluk sınıf ortamlarını değerlendirmek için elverişli ve güvenilir bir araç olduğu ortaya koymaktadır (Kayış, 2016). 
Sonuç olarak, oluşturulan ölçme aracının faktör yapılarının ve maddelerinin literatürde sınıf ortamını değerlendirmek için vurgulanan kriterler ve alanda kabul görmüş birçok ölçme aracının faktör yapıları ve maddeleri ile uyumlu görünmesi ve yapılan analizlerin sonuçları ölçeğin geçerli ve güvenilir bir ölçme aracı olduğuna dair kanıt oluşturmaktadır.

Bu çalışma Türkiye'nin 43 ilinde bulunan MEB’e bağlı devlet ve özel okullarda çalışan okul öncesi öğretmenlerinden alınan bilgiler ile sınırlıdır. Veriler 2018-2019 yılları arasında sağlanmıştır. Bu nedenle geçen süre zarfında gelişen ya da değişen okullar ve öğretmenler göz önünde bulundurularak değerlendirmeler yapılması gerekmektedir.

\section{Öneriler}

Bu çalışma doğrultusunda Türkiye'nin 43 iline ulaş1labilmiştir. Daha fazla ile ulaşılarak güvenirlik testi gerçekleştirilebilir. Ayrıca bölgesel olarak da illerin ve okulların çeşitliliği arttırılarak çalışma yürütülebilir. Gelecekte yapılacak diğer araştırmalarda farklı sınıf düzeylerindeki ortamların değerlendirilmesine yönelik araçlar geliştirilebilir. Farklı ülkelerdeki öğrenme ortamlarının değerlendirildiği kültürlerarası çalışmalar yapılabilir. Geliştirilen ölçme aracının alanyazında okul öncesi sınıf ortamını değerlendirmeye yönelik var olan ölçme araçlarıyla (gözlemi içeren ölçekler) birlikte kullanılmasıyla çoklu bakış açılarının yer aldığı değerlendirmeler yapılabilir. Okul öncesi dönemde çocuklara sağlanan sınıf ortamının uzun vadeli etkileri göz önüne alındığında, sınıf ortamlarının değerlendirilerek düzenlenmesi bağlamında müdahaleler yapılabilir. Benzer şekilde, erken çocukluk eğitimi politikalarının geliştirilmesinde var olan sınıf ortamlarının değerlendirilmesi ve iyileştirilmesinde bir araç olarak kullanılabilir.

Etik Kurul İzin Bilgisi: Bu araştırma, Ankara Üniversitesi Sosyal Bilimler Alt Etik Kurulu’nun 30/04/2018 tarihli 6/91 sayılı kararı ile alınan izinle yürütülmüştür.

Yazar Çıkar Çatışması Bilgisi: Araştırmada yer alan yazarların herhangi bir çıkar çatışmaları bulunmamaktadır.

Yazar Katkısı: Bütün yazarlar eşit ölçüde katkıda bulunmuştur.

\section{Kaynakça}

Aina, O. E., \& Cameron, P. A. (2011). Why does gender matter? Counteracting stereotypes with young children. Dimensions of Early Childhood, 39(3), 11-20. Retrieved from https://eric.ed.gov/?id=EJ945697 
26 D.E., Çakar, K.Z., Deniz, N. Teke, T. Baş, E. Kılınçcı ve N, Aksoy/ Pamukkale Üniversitesi Eğitim Fakültesi Dergisi, 56, 1-34, 2022

Aktulun, Ö. U., \& Kiziltepe, G. I. (2018). Using learning centers to improve the language and academic skills of preschool children. World Journal of Education, 8(6), 32-44. https://doi.org/10.5430/wje.v8n6p32.

Arıkan, A. (2016). Highscope programı. In F. Temel (Ed.), Erken çocukluk eğitiminde yaklaşımlar ve programlar (pp. 359-403). Ankara: Vize Yayıncılık.

Azlina, W., \& Zulkiflee, A. S. (2012). A pilot study: The impact of outdoor play spaces on kindergarten children. Procedia-Social and Behavioral Sciences, 38, 275-283. https://doi.org/10.1016/j.sbspro.2012.03.349.

Babaroğlu, A. (2018). Eğitim ortamları açısından okul öncesi eğitim kurumları. Abant İzzet Baysal Üniversitesi Eğitim Fakültesi Dergisi, 18(3), 1313-1330. https://doi.org/10.17240/aibuefd.2018.18.39790-471118

Bandura, A. (1977). Social learning theory. London: Prentice Hall.

Bandura, A. (1989). Human agency in social cognitive theory. American Psychologist, 44(9), 1175-1189. https://doi.org/10.1037/0003-066X.44.9.1175

Bandura, A. (1995). Self-Efficacy in Changing Societies. In A. Bandura (Ed.). Exercise of personal and collective efficacy in changing societies (pp. 1-45). Cambridge: Cambridge University Press.

Belfield, C., Nores, M., Barnett, W. S., \& Schweinhart L. (2005). Updating the economic impacts of the High/Scope Perry Preschool Program. Educational Evaluation and Policy Analysis, 27(3), 245-262. https://doi.org/10.3102/01623737027003245

Bjorklund, D. F., \& Causey, K. B. (2017). Children's thinking: Cognitive development and individual differences. Sage Publications.

Bodrova, E., \& Leong, D. J. (2017). Zihnin araçlarl: Erken çocukluk eğitiminde Vygotsky yaklaşımı. (G. Haktanır, Çev. Eds; T. Güler, F. Şahin, A. Yılmaz, E. Kalkan, Çev.) Ankara: Anı Yayıncılık (1996).

Botsoglou, K., Beazidou, E., Kougioumtzidou, E., \& Vlachou, M. (2019). Listening to children: using the ECERS-R and Mosaic approach to improve learning environments: A case study. Early Child Development and Care, 189(4), 635-649. https://doi.org/10.1080/03004430.2017.1337006 
Brodin, J., \& Renblad, K. (2020). Improvement of preschool children's speech and language skills. Early Child Development and Care, 190(14), 2205-2213. https://doi.org/10.1080/03004430.2018.1564917

Broekhuizen, M. L., Mokrova, I. L., Burchinal, M. R., Garrett-Peters, P. T., \& Family Life Project Key Investigators. (2016). Classroom quality at pre-kindergarten and kindergarten and children's social skills and behavior problems. Early Childhood Research Quarterly, 36, 212-222. https://doi.org/10.1016/j.ecresq.2016.01.005

Bronfenbrenner, U. (1976). The experimental ecology of education. Educational Researcher, 5(9), 5-15. https://doi.org/10.3102/0013189X005009005

Bronfenbrenner, U. (1994). Ecological models of human development. In P. Peterson, E. Baker, B. McGaw, (Eds.). International Encyclopedia of Education, (Vol. 3, 2nd ed.). Oxford: Elsevier.

Büyüköztürk, Ş. (2020). Sosyal bilimler için veri analizi el kitabı (28.Baskı). Ankara: Pegem Yayınları.

Büyüköztürk, Ş., Çakmak, E. K., Akgün, Ö. E., Karadeniz, Ş. \& Demirel, F. (2016). Bilimsel araştırma yöntemleri. Ankara: Pegem Akademi.

Che Ahmad, C. N., \& Amirul, N. J. (2017). The effect of the physical learning environment on students' health, enjoyment, and learning. Jurnal Pendidikan Sains dan Matematik Malaysia, 7(1), 47-55. https://doi.org/10.37134/jpsmm.vol7.no1.4.2017

Choi, H. H., Van Merriënboer, J. J., \& Paas, F. (2014). Effects of the physical environment on cognitive load and learning: Towards a new model of cognitive load. Educational Psychology Review, 26(2), 225-244. https://doi.org/10.1007/s10648-014-9262-6.

Çobanoğlu, R., Yıldırım, A., \& Aydın, Y. Ç. (2020). Okul öncesi eğitimin niteliğine bir bakış: Aileler, öğretmenler ve çalışma koşulları ile ilgili sorunlar. Eğitimde Nitel Araştırmalar Dergisi, 8(2), 407-430. https://doi.org/10.14689/issn.2148-624.1.8c.2s.1m.

Çokluk, Ö., Şekercioğlu G., \& Büyüköztürk Ş. (2014). Sosyal bilimler için çok değişkenli istatistik SPSS ve LISREL uygulamalart. Ankara: Pegem Yayıncılık.

Demiriz, S., Karadağ, A., \& Ulutaş, I. (2003). Okul öncesi eğitim kurumlarında eğitim ortamı ve donanım. Ankara: Anı Yayınc1lık. 
28 D.E., Çakar, K.Z., Deniz, N. Teke, T. Baş, E. Kılınçcı ve N, Aksoy/ Pamukkale Üniversitesi Eğitim Fakültesi Dergisi, 56, 1-34, 2022

DeVellis, R. F. (2017). Ölçek geliştirme: Kuram ve uygulamalar. (T. Totan, Çev.). Ankara: Nobel Yayıncılık (2012).

Epstein, A. S., \& Schweinhart, L. J. (2018). Educational tenets of the HighScope curriculum. In M. Fleer, \& B. Oers (Eds.), International Handbook of Early Childhood Education (pp. 1347-1377). Dordrecht: Springer.

Erdiller, Z. B. (2010). Erken çocukluk eğitiminde temel kuram ve yaklaşımlar. In İ. H. Diken (Ed.). Erken çocukluk ĕgitimi (pp. 56-90). Ankara: Pegem Yayıncılık.

Erkuş, A. (2019). Psikolojide ölçme ve ölçek geliştirme-I: Temel kavramlar ve işlemler (4. Baskı). Ankara: Pegem Yayınları.

Fish, M. C., \& Dane, E. (2000). The classroom systems observation scale: Development of an instrument to assess classrooms using a systems perspective. Learning Environments Research, 3(1), 67-92. https://doi.org/10.1023/A:1009979122896

Fraenkel, J. R. \& Wallen, N. E. (2009). How to design and evaluate research in education. New York: McGraw Hall.

Fraser, B. J., \& Fisher, D. L. (1982). Evaluation studies: predictive validity of My Class Inventory. Studies in Educational Evaluation, 8(2), 129-140. https://doi.org/10.1016/0191-491X(82)90004-9

Gagnon, S. G., Kidder-Ashley, P., \& Nickerson, A. B. (2017). Assessment of school and classroom environment. In B. Bracken and R. Nagle (Eds). Psychoeducational assessment of preschool children (pp. 173-194). Routledge.

Goble, P., Hanish, L. D., Martin, C. L., Eggum-Wilkens, N. D., Foster, S. A., \& Fabes, R. A. (2016). Preschool contexts and teacher interactions: Relations with school readiness. Early Education and Development, 27(5), 623-641. https://doi.org/10.1080/10409289.2016.1111674.

Gorsuch, R. L. (1983). Factor Analysis (2nd ed.). Hillsdale, NJ: Lawrence Erlbaum Associates.

Güçlü, M., \& Altan, A. E. (2020). Türkiye'de okul öncesi eğitim alanında görülen sorunlar üzerine genel bir değerlendirme. Uluslararası Sosyal Araştırmalar Dergisi, 13(69), 1051-1061. https://doi.org/10.17719/jisr.2020.4019.

Gültekin Akduman, G. (2012). Okul öncesi eğitim tanımı ve önemi. In G. Uyanık Balat (Ed.), Okul öncesi ĕgitime girişs (pp. 2-15). Ankara: Pegem Akademi. 
Hancock, C. L., \& Carter, D. R. (2016). Building environments that encourage positive behavior. Young Children, 71(1), 68-73.

Harms, T., Clifford, R. M. \& Cryer, D. (2005). Early Childhood Environment Rating Scale (ECERS-R): Revised Edition. New York: Teachers College Press.

Havu-Nuutinen, S., \& Niikko, A. (2014). Finnish primary school as a learning environment for six-year-old preschool children. European Early Childhood Education Research Journal, 22(5), 621-636. https://doi.org/10.1080/1350293X.2014.969084.

Ho, R. (2006). Handbook of univariate and multivariate data analysis and interpretation with SPSS. Boca Raton: CRS Press.

Hohmann, M., \& Weikart, D. P. (2000). Küçük çocukların eğitimi. (S. Saltiel Kohen and Ü. Öğüt, Çev. Eds). İstanbul: Hisar Eğitim Vakfi. (1995).

Holt, N. (2010). Bringing the High Scope approach to your early years practice. USA: Routledge.

Horn, J. L. (1965). A rationale and test for the number of factors in factor analysis. Psychometrica, 30(2), 179-185. Retrieved from https://link.springer.com/article/10.1007/BF02289447

Hui, A. N., Lee, M. L., Yeung, P. S., Chick, J. H., Ho, A. K., \& Ng, C. K. (2017). Enhancement of Quality in Early Childhood Education: Using the Early Childhood Environment Rating Scale-Extension (ECERS-E) and Revised (ECRES-R) as Formative Assessment Tools for Professional Development-An Experience from Hong Kong. Asia-Pacific Journal of Research in Early Childhood Education, 11(3), 1-16. https://doi.org/10.17206/APJRECE.2017.11.3.1.

Hyson, M. C., Hirsh-Pasek, K., \& Rescorla, L. (1990). The classroom practices inventory: An observation instrument based on NAEYC's guidelines for developmentally appropriate practices for 4-and 5-year-old children. Early Childhood Research Quarterly, 5(4), 475494. https://doi.org/10.1016/0885-2006(90)90015-S.

Jöreskog, K. G., \& Sörbom, D. (1993). LISREL 8: Structural Equation Modeling with the SIMPLIS Command Language. Lincolnwood: Scientific Software International.

Kalaycı, Ş. (2006). SPSS uygulamalı çok değişkenli istatistik teknikleri. Ankara: Asil Yayınları. 
30 D.E., Çakar, K.Z., Deniz, N. Teke, T. Baş, E. Kılınçcı ve N, Aksoy/ Pamukkale Üniversitesi Eğitim Fakültesi Dergisi, 56, 1-34, 2022

Karaküçük, S. A. (2008). Okul öncesi eğitim kurumlarında fiziksel/mekansal koşulların incelenmesi: Sivas ili örneği. Cumhuriyet Üniversitesi Fen-Edebiyat Fakültesi Sosyal Bilimler Dergisi, 32(2), 307-320. Retrieved from http://eskidergi.cumhuriyet.edu.tr/makale/1843.pdf.

Kayış A. (2016). Güvenirlik analizi. In Ş. Kalaycı (Ed.), SPSS uygulamalı çok değişkenli istatistik teknikleri, (pp. 403-419). Ankara: Asil Yayınları.

Kline, R. B. (2005). Principles and practice of structural equation modeling. New York: Guilford Publications.

Knauf, H. (2019). Physical environments of early childhood education centres: Facilitating and inhibiting factors supporting children's participation. International Journal of Early Childhood, 51(3), 355-372. https://doi.org/10.1007/s13158-019-00254-3.

Kostelnik, M. J., Soderman, A. K., Whiren, A. P., \& Rupiper, M. L. (2015). Developmentally appropriate curriculum: Best practices in early childhood education (6th ed.). Upper Saddle River, NJ: Prentice Hall.

Kragh-Müller, G., \& Ringsmose, C. (2015). Educational quality in preschool centers. $\begin{array}{lll}\text { Childhood } \quad \text { Education, } & \text { 198-205. }\end{array}$ https://doi.org/10.1080/00094056.2015.1047311.

Kravtsova, E. (2017). The sense and the meaning of cultural-historical theory of L. S. Vygotsky. CRI-SAS International Journal: Vygotsky's Heritage: Innovation in Education, 4(1), 35-47. https://doi.org/10.51657/ric.v4i1.40991.

Kubanç, Y. (2014). Okul öncesi eğitim kurumlarının fiziki durumunun incelenmesi. Journal of International Social Research, 7(31), 675-688. Retrieved from https://eds.p.ebscohost.com/eds/pdfviewer/pdfviewer?vid=0\&sid=e966131a-7049$\underline{4 d e 8-8 a 2 c-43075 a 91 a 595 \% 40 r e d i s}$.

Lim, P. P. L., \& Bahauddin, A. (2019). Factors for consideration to achieve a contextually appropriate physical environment in Malaysian preschools. International Journal of $\begin{array}{llll}\text { Early } \quad \text { Years } & \text { 27(4), }\end{array}$ https://doi.org/10.1080/09669760.2018.1507903.

Lorsbach, A., \& Jinks, J. (1999). Self-efficacy theory and learning environment research. Learning Environments Research, 2(2), 157-167. Retrieved from https://link.springer.com/article/10.1023/A:1009902810926. 
Mashburn, A. J., Pianta, R. C., Hamre, B. K., Downer, J. T., Barbarin, O. A., Bryant, D., ... \& Howes, C. (2008). Measures of classroom quality in prekindergarten and children's development of academic, language, and social skills. Child Development, 79(3), 732749. https://doi.org/10.1111/j.1467-8624.2008.01154.x.

Maxwell, L. E. (2007). Competency in childcare settings: The role of the physical environment. $\begin{array}{llll}\text { Environment } \quad \text { and } & \text { 39(2), }\end{array}$ https://doi.org/10.1177/0013916506289976.

McGurk, H. (2017). Issues in childhood social development. USA: Routledge.

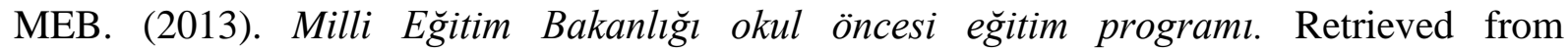
https://ttkb.meb.gov.tr/www/ogretim-programlari/icerik/72.

Mohamed, A. H. H., \& Marzouk, S. A. F. M. (2016). The association between preschool classroom quality and children's social-emotional problems. Early Child Development and Care, 186(8), 1302-1315. https://doi.org/10.1080/03004430.2015.1092140.

Obaki, S. O. (2017). Impact of Classroom Environment on Children's Social Behavior. International Journal of Education and Practice, 5(1), 1-7. https://doi.org/10.18488/journal.61/2017.5.1/61.1.1.7.

Ocak, S. (2010). The effects of child-teacher relationships on interpersonal problem-solving skills of children. Infants \& Young Children, 23(4), 312-322. https://doi.org/10.1097/IYC.0b013e3181f27769.

Ozkal, K., Tekkaya, C., Cakiroglu, J., \& Sungur, S. (2009). A conceptual model of relationships among constructivist learning environment perceptions, epistemological beliefs, and learning approaches. Learning and Individual Differences, 19(1), 71-79. https://doi.org/10.1016/j.lindif.2008.05.005.

Özgün, Ö. (2015). Her yönüyle okul öncesi eğitim. In F. Turan and A. İ. Yükselen (Ed.). Çocuk gelişimi kuramları (pp. 46-82). Ankara: Hedef Yayıncılık.

Özsırkıntı, D., Akay., C. \& Yılmaz Bolat, E. (2014). Okul öncesi öğretmenlerinin okul öncesi eğitim programı hakkındaki görüşleri adana ili örneği. Ahi Evran Üniversitesi Kırşehir Eğitim Fakültesi Dergisi, 15(1), 313-331. Retrieved from https://dergipark.org.tr/tr/pub/kefad/issue/59467/854538. 
32 D.E., Çakar, K.Z., Deniz, N. Teke, T. Baş, E. Kılınçcı ve N, Aksoy/ Pamukkale Üniversitesi Eğitim Fakültesi Dergisi, 56, 1-34, 2022

Pallant, J. (2017). SPSS kullanma kılavuzu SPSS ile adım adım veri analizi (S. Balcı and B. Ahi, Çev.). Ankara: Anı Yayıncılık.

Parshekofti, N. S. (2014). Studying the Effect of Physical Space of Learning Environment on Students' Academic Achievement Motive: (Case Study: Payam-e-Nour University, Qeshm International Branch). International Journal of Academic Research in Business and Social Sciences, 4(7), 111-119. https://doi.org/10.6007/IJARBSS/V4-I7/994.

Phillips, B. M., Zhao, Y., \& Weekley, M. J. (2018). Teacher language in the preschool classroom: Initial validation of a classroom environment observation tool. Early $\begin{array}{lll}\text { Education } \quad \text { and } & \text { 29(3), }\end{array}$ https://doi.org/10.1080/10409289.2017.1408371.

Pianta, R. C., La Paro, K. M., \& Hamre, B. K. (2008). Classroom assessment scoring system: Manual K-3. London: Paul H Brookes Publishing.

Reddy, L. A., Fabiano, G. A., \& Dudek, C. M. (2013). Concurrent validity of the classroom strategies scale for elementary School-Observer Form. Journal of Psychoeducational Assessment, 31(3), 258-270. https://doi.org/10.1177/0734282912462829.

Roeser, R. W., Midgley, C., \& Urdan, T. C. (1996). Perceptions of the school psychological environment and early adolescents' psychological and behavioral functioning in school: The mediating role of goals and belonging. Journal of Educational Psychology, 88(3), 408-422. https://doi.org/10.1037/0022-0663.88.3.408.

Sandberg, G. (2017). Different children's perspectives on their learning environment. European Journal of Special Needs Education, 32(2), 191-203. https://doi.org/10.1080/08856257.2016.1216633.

Senemoğlu, N. (2015). Gelişim, ögrrenme ve öğretim kuramdan uygulamaya. Ankara: Yarg1 Akademi Yayınları.

Shaari, M. F., \& Ahmad, S. S. (2016). Physical learning environment: Impact on children school readiness in Malaysian preschools. Procedia-Social and Behavioral Sciences, 222(2016), 9-18. https://doi.org/10.1016/j.sbspro.2016.05.164.

Sheridan, S., \& Pramling Samuelsson, I. (2013). Preschool a source for young children's learning and well-being. International Journal of Early Years Education, 21(2-3), 207222. https://doi.org/10.1080/09669760.2013.832948. 
Siwatu, K. O., Putman, S. M., Starker-Glass, T. V., \& Lewis, C. W. (2015). The Culturally Responsive Classroom Management Self-Efficacy Scale: Development and initial $\begin{array}{lll}\text { validation. } \quad \text { Erban } & \text { 8ducation, }\end{array}$ https://doi.org/10.1177/0042085915602534.

Solak, N. (2007). Adana il merkezinde bulunan okulöncesi eğitim kurumlarında kalitenin incelenmesi (Unpublished master dissertation). Çukurova Üniversitesi Sosyal Bilimleri Enstitüsü, Adana.

Spencer, C. J. (2006). Children and their environments: Learning, using, and designing spaces. USA: Cambridge University Press.

Stanulis, R. N., \& Manning, B. H. (2002). The teacher's role in creating a positive verbal and nonverbal environment in the early childhood classroom. Early Childhood Education Journal, 30(1), 3-8. https://doi.org/10.1023/A:1016581612865.

Şahin, S. (2010). 0 - 6 yaş arası çocukların temel gelişimsel özellikleri: fiziksel ve sosyalduygusal gelişim. In İ. Diken (Ed.). Erken çocukluk eğitimi (pp. 92-133). Ankara: Pegem Yayıncılık.

Tabachnick, B. G., \& Fidell, L. S. (2015). Using multivariate statistics. (M. Baloğlu, Çev.). Ankara: Nobel Yayınları.

Tadjic, M., Martinec, M., \& Farago, A. (2017). The impact of physical settings on pre-schoolers classroom organization. European Journal of Education Studies, 1(1), 14-36. http://dx.doi.org/10.46827/ejes.v0i0.2.

Trawick-Smith, J. (2014). Erken çocukluk döneminde gelişim: Çok kültürlü bir bakış açısı. (B. Akman, Çev.). Ankara: Nobel Yayınları.

Tuğluk, M. N., \& Özkan, B. (2019). MEB 2013 okul öncesi eğitim programının 21. Yüzyıl becerileri açısından analizi. Journal of Primary Education, 1(4), 29-38. Retrieved from https://dergipark.org.tr/tr/pub/temelegitim/issue/49907/634024.

Vosniadou, S., Ioannides, I., Dimitrakopoulou, A., \& Papademetriou, E. (2001). Designing Learning Environments to Promote Conceptual Change in Science. Learning and Instruction, 11(4-5), 381-419. https://doi.org/10.1016/S0959-4752(00)00038-4.

Vygotsky, L. S. (1978). Mind in society: The development of higher psychological processes (M. Cole and S. Scribner, Çev. Ed.). London: Harvard University Press. 
34 D.E., Çakar, K.Z., Deniz, N. Teke, T. Baş, E. Kılınçcı ve N, Aksoy/ Pamukkale Üniversitesi Eğitim Fakültesi Dergisi, 56, 1-34, 2022

Weinstein, C. S. (1979). The physical environment of the school: A review of the research. Review of Educational Research, 49(4), 577-610. https://doi.org/10.3102/00346543049004577.

Wilson, B. G. (1996). Constructivist learning environments: Case studies in instructional design. U.S.A: Educational Technology Publication.

Wiltshire, M. (2018). Understanding the High Scope Approach: Early years education in practice. USA: Routledge.

Wolter, I., Braun, E., \& Hannover, B. (2015). Reading is for girls!? The negative impact of preschool teachers' traditional gender role attitudes on boys' reading related motivation $\begin{array}{llllll}\text { and } & \text { skills. } & \text { Frontiers }\end{array}$ https://doi.org/10.3389/fpsyg.2015.01267.

Zamani, Z. (2016). The woods is a more free space for children to be creative; their imagination kind of sparks out there: Exploring young children's cognitive play opportunities in natural, manufactured, and mixed outdoor preschool zones. Journal of Adventure Education and Outdoor Learning, 16(2), 172-189. https://doi.org/10.1080/14729679.2015.1122538. 
Early Childhood Classroom Environment Assessment Scale (ECCEAS):

\author{
A Validity and Reliability Study* \\ Dilek Acer Çakar**, Kaan Zülfikar Deniz ${ }^{* * *}$, Nergiz Teke ${ }^{* * * *}$, Tuğba Baş ${ }^{* * * * *}$, Emine \\ Kilınçc1 $^{* * * * * *}$, Nur Aksoy ${ }^{* * * * * * *}$
}

- Received: 08.07.2021 • Accepted: 16.02.2022 • Online First: 16.02.2022

\begin{abstract}
The study aim was to develop the Early Childhood Classroom Environment Assessment Scale (ECCEAS) to measure the quality of preschool classroom environments as well as the scale validity and reliability. This study was conducted using survey research design and the study sample consisted of 312 preschool teachers determined by maximum diversity sampling. First, Principal Components Analysis (PCA) and then Confirmatory Factor Analysis (CFA) were performed. Cronbach alpha internal consistency reliability was calculated for reliability analysis. As a result of the analysis, it was determined that the scale consisted of 38 items and 5 factors and the factors explained for a total common variance of 52.13\%. As a result of the analyzes, when the goodness of fit index values of the scale (RMSEA=.076, S-RMR=.025, GFI=.67, AGFI=.63, NFI=.79, $\mathrm{NNFI}=.89$, CFI=.90, IFI=.90), It is seen that GFI, AGFI, NFI values corresponded to poor fit, whereas the NNFI, CFI, and IFI corresponded to good fit. The Cronbach alpha were $.86, .84, .74$, .66 , and .84, respectively. Thus, a valid and reliable scale was obtained.
\end{abstract}

Keywords: early childhood, classroom environment, environment assessment, validity, reliability

\title{
Cited:
}

Çakar, D.E, Deniz, K.Z., Teke, N., Baş, T., Kılınçcı, E., \& Aksoy, N. (2022). Early childhood classroom environment assessment scale (ECCEAS): A validity and reliability study. Pamukkale University Journal of Education, 56, 1-34, doi:10.9779.pauefd.961254

\footnotetext{
${ }^{*}$ VIII. Presented as an oral presentation at the International Eurasian Educational Research Congress (7-10 July 2021, Aksaray, Turkey).

** Prof. Dr., Ankara University, Faculty of Educational Sciences, https://orcid.org/0000-0002-0608-2073, dilekacer@yahoo.com (Corresponding Author)

Assoc. Prof. Dr., Ankara University, Faculty of Educational Sciences, https://orcid.org/0000-0003-0920-538X, zlfkrdnz@yahoo.com

Res. Assist., Bartın University, Faculty of Education, https://orcid.org/0000-0002-7281-7509, nergizteke42@gmail.com

***** Res. Assist., Bartın University, Faculty of Education, https://orcid.org/0000-0003-1093-2445, tugbakarakoc32@gmail.com

Ph.D. student, University of Wisconsin-Madison, School of Education, https://orcid.org/0000-0002-3848-0404, kilincci@,wisc.edu

R****** Assist., Kafkas University, Faculty of Education, https://orcid.org/0000-0002-8693-0588, nur.aksoy93@gmail.com
} 


\section{Introduction}

It has been indicated that the development of a child is largely completed within the age range of 0 8 years old (Bjorklund \& Causey, 2017; Brodin \& Renblad, 2019; McGurk, 2017). In this age range, which is a very critical period of development, one crucial point that needs to be taken into consideration for a child's healthy development is providing him/her an environment full of rich stimulation that leads to great exploration and learning (Broekhuizen, Mokrova, Burchinal, GarrettPeters, \& Family Life Project Key Investigators, 2016; Mashburn, Pianta, Hamre, Downer, Barbarin, Bryant, \& Howes, 2008). Importantly, the effectiveness of the learning environment directly affects the children's cognitive, social and emotional attainment, academic achievement, self-esteem, and attitudes towards learning as part of the overall learning and development experience (Belfield, Nores, Barnett \& Schweinhart, 2005; Broekhuizen et al., 2016; Gagnon, Kidder-Ashley, \& Nickerson, 2017; Mashburn et al., 2008; Obaki, 2017; Parshekofti, 2014; Sheridan \& Pramling Samuelsson, 2013). Mohamed and Marzouk (2016) reveal that preschool classroom environments are associated with children's social skills, peer interactions, child-teacher interaction as well as participation and collaboration in classroom activities. It is also found that problems such as attention difficulties, aggression issues, depression, and emotional control challenges occur less often in appropriate classroom settings. Learning environments are known to play a critical role in the child's social (Obaki, 2017), linguistic, emotional, and cognitive development (Choi, Van Merriënboer, \& Paas, 2014) as well as their overall learning and development (Che Ahmad \& Amirul, 2017; Parshekofti, 2014). As a result, it is important to provide a safe, comfortable, and rich environment for children to adopt positive behaviors while learning necessary life skills.

In addition to a learning environment being effective, it is also important that the environment be evaluated in an appropriate and comprehensive manner. The assessment of learning environments is important as well-prepared learning environments are known to contribute significantly to the development, learning aspirations, interests, and long-term academic skills of children (Gagnon, Kidder-Ashley, \& Nickerson, 2017). Standardized instruments, which provide the most reliable way of making assessments, help to identify the strengths and weaknesses of important variables within the learning environment as well as facilitate needed improvements, and as a result, support children's overall development and learning (Hui, Lee, Yeung, Chick, Ho, \& Ng, 2017). In this respect, the researchers in this current study aimed at developing an Early Childhood Classroom Environment Assessment Scale (ECCEAS) more suited for use in Turkey, and in doing so, conduct a validity and reliability analysis of the newly developed ECCEAS.

\section{Importance of learning environment}

The learning environment for a young child is defined as an environment in which the learner learns and interprets information, interacts with peers and adults, and uses materials and tools. In addition, 
D.E., Çakar, K.Z., Deniz, N. Teke, T. Baş, E. Kılınçcı \& N, Aksoy /Pamukkale University Journal of Education, 56, 1-34, 20223 the learning environment consists of social, psychological, and pedagogical aspects where the learning occurs as well as where the learner can utilize resources to make sense of situations and/or events to find meaningful solutions for problem solving (Ozkal, Tekkaya, Cakiroglu, \& Sungur, 2009; Sandberg, 2017; Wilson, 1996). It is seen that children interact closely with teachers in preschool education classroom environments. For this reason, it is very important for preschool teachers to support children by providing the necessary physical and social environment in the classroom environment. Depending on the age and developmental characteristics of the child, the child begins to know the environment in more detail. Environments prepared in accordance with the needs of the child support the child to become independent, self-confident and high self-esteem individuals (Demiriz, Karadağ, \& Ulutaş, 2003). A child's learning environment can be classified as their social and physical environment (Weinstein, 1979; Roeser, Midgley, \& Urdan, 1996). The social environment consists of individuals and the relationships that the child establishes with them, while the physical environment consists of the structure and the materials used. Both the social and physical environment in which the child is located plays an important role in the development of the child. An environment that activates the senses through various stimulants can also improve the child's empathy, idea generation and creativity skills by contributing to the child's mental development (Gültekin Akduman, 2012). According to Havu-Nuutinen and Niikko (2014), the preschool learning environment is defined through three dimensions: physical-aesthetic, psychosocial, and pedagogical-ethical. The physical-aesthetic environment includes the environment built from natural materials which fulfills the entertainment and aesthetic experiences of children and teachers. The psycho-social environment refers to an accepting environment that encourages children's curiosity, interests, learning motivation, activities, and self-orientation. The pedagogicalethical environment comprises curriculum practices, teaching and activity organization, care, education principles, teaching perspectives, and the interactions between children and their parents as considered through the ethical dimensions of behavior.

Physical regulation of the environment drives the behavior and choices of children by encouraging various activities that suit a variety of preferences. Preschool environments with highquality spatial and aesthetic qualities, designed by using safe, suitable materials and furniture, are conducive to learning and maximize the development and learning of children (Shaari \& Ahmad, 2016). In Zamani's (2016) study, it is found that accessible natural materials in environments where natural and artificial elements coexist are important for children's learning of science through use of discovery and drama. For example, the High-Scope Approach, which is one of the basic approaches utilized in the development of the preschool curriculum (MEB, 2013) used in preschool educational institutions within Turkey, requires an adequate amount as well as a variety of open-ended materials for both individual and group activities. It is important that these materials are arranged according to the Find-Use-Place principle on shelves and in transparent containers suitable for the height of young 
4 D.E., Çakar, K.Z., Deniz, N. Teke, T. Baş, E. Kılınçcı \& N, Aksoy /Pamukkale University Journal of Education, 56, 1-34, 2022 children (Wiltshire, 2018). Also, it is critical to organize learning centers where adults and children can easily see one another in the classroom as well as interact and work in accordance with the interests of children (Aktulun \& Kiziltepe, 2018; Kostelnik, Soderman, Whiren, \& Rupiper, 2015). According to the High-Scope Approach, learning centers/spaces should be divided using various items, such as furniture and even fences that are appropriate to the height of young children as well as store and exhibit materials that children can easily access. The materials used to separate these learning centers/spaces should not be too high, causing the children to be unable to see their friends and/or determine where they want to play next. In addition, the teacher should be able to clearly see what children are doing and involved in. Furthermore, the labels used for learning centers/areas should not only identify those present, but also include appropriate expressions for children and/or be expressed using child appropriate symbols. By providing learning centers/spaces names that are meaningful to children and that explain what the center is designated for, helps children to control their own play as well as develop independence (Holt, 2010). Importantly, materials utilized in learning centers should incorporate nature into the classroom environment. For example, it is important to use natural materials such as leaves, soil, branches, bark, stones, and water as part of learning center activities. In addition to natural materials, care should be taken to include pleasant color schemes and textures within the classroom environment (Şahin, 2010).

A carefully designed physical environment influences children's choices and discoveries as well as promotes their ability to take initiative, builds self-esteem and social skills, and helps them to take control of their own actions and responsibilities (Botsoglou, Beazidou, Kougioumtzidou, \& Vlachou, 2019). Children learn more easily in an environment which has flexibility and fluency, where they can act on their own, work independently or in groups, interact socially and express their individuality, feel that they belong and feel safe, access materials easily, and can more readily be involved in educational processes (Lim \& Bahauddin, 2019; Knauf, 2019, Spencer, 2006, Tadjic, Martinec, \& Farago, 2017). In addition, natural environments can be used to encourage children to socialize and participate in various play activities (Azlina \& Zulkiflee, 2012).

Regarding other dimensions of the educational environment, the social environment consists of individuals and the child's relationships with them, while the physical environment consists of the buildings and materials used. Vygotsky states that the child's social environment is important for his/her cognitive development. He describes the source of children's learning as the people that are around them as well as their immediate social world. According to Vygotsky, a child's zone of proximal development within the classroom can be advanced through scaffolding established and carried out by the teacher. Importantly, in most cases, the skills that a child can do with support and without support may vary between children. What the child can do initially with support, will in the later period of development become what the child can do independently (Bodrova \& Leong, 2017). According to Vygotsky (1978), children regulate their own behavior by observing the behavior of 
D.E., Çakar, K.Z., Deniz, N. Teke, T. Baş, E. Kılınçcı \& N, Aksoy /Pamukkale University Journal of Education, 56, 1-34, 20225 others. They apply the rules observed through others' actions before applying them themselves, and as a result, when the regulating skill is performed by a more capable person, such as a teacher or parent it provides correct guidance leading to the child's appropriate self-regulation. From another perspective, the High-Scope Approach is also based on effective learning and advocates the idea that children should have a special area of study where they can act independently, experiment, work with friends, and have their own space for study (Epstein \& Schweinhart, 2018; Hohmann \& Weikart, 2000). Thus, children's behaviors of adopting the classroom environment activities, making plans, and choosing the appropriate tools in line with their plans (Arikan, 2016) contributes to the development of self-regulation skills by requiring the children to put the materials they use back into the assigned place.

Another type of skill that can be associated with individual competence, such as selfregulation, is self-efficacy. Children can become aware of their own abilities through repetitive experiences presented to them during their own levels of development, and thus overcome experiences where they have previously failed and do so without being affected by negativity (Bandura, 1989). Importantly, self-efficacy depends on the elements of classroom environment because the order and openness of the classroom environment allows skills to be assessed more accurately (Lorsbach \& Jinks, 1999). Teachers who strongly believe in the ability to promote learning can create mastery for their students through experiences, yet teachers who doubt themselves about teaching activities can create classroom environments that adversely affect students' abilities and cognitive development (Bandura, 1995). In addition, a teacher can not only motivate a child to achieve his/her goal, but also to develop his/her leadership skills (Şahin, 2010). As a result, this contributes to the perception of high self-efficacy, which Bandura argues can be an important factor in shaping behavior. In order for children's self-efficacy to be high, it is crucial for teachers to consider children's individual needs, have various activities that are appropriate for their developmental levels, and support cooperation among children within the classroom rather than comparing them (Senemoğlu, 2015).

In some cases, children can learn by simply observing without cooperation or interaction but the most important factor in learning through observation is having the appropriate model. According to Bandura (1977), the child tends to show the model behaviors he or she observes according to their states of reinforcement. Therefore, by communicating the message to other children regarding the appropriateness or inappropriateness of a behavior, the teacher reinforces the positive behavior of children (Trawick-Smith, 2014). As a result, for children to acquire positive behaviors as well as feel a sense of accomplishment, the teacher must provide appropriate environments and opportunities for the children's learning and growth. 
6 D.E., Çakar, K.Z., Deniz, N. Teke, T. Baş, E. Kılınçcı \& N, Aksoy /Pamukkale University Journal of Education, 56, 1-34, 2022

\section{Role of teacher}

According to the Ecological Theory, development is a product of a child's interaction with the environment (Bronfenbrenner, 1994). The focus is placed on the different situations and contexts children face within the development process as well as their interactions with children's roles inside these contexts (Özgün, 2015). It is suggested that the cognitive, social, emotional, biological, and psychological character of the environment allows a child to communicate with their environment at its core and react to influences from within the environment (Erdiller, 2010). The microsystem, which is one of five systems, includes factors in the child's immediate vicinity such as the daily events he/she encounters and his/her relationship with people. Teachers are in this system and one of the most important factors in the preparation of environments where children can develop their skills and achieve new learning in line with their interests is the role of the teacher (Bronfenbrenner, 1976; Bronfenbrenner, 1994). Goble, Hanish, Martin, Eggum-Wilkens, Foster, and Fabes (2016) find that teachers' direct interaction with children within classroom activities (including activities directed by children) leads to positive contributions for children's overall development, especially in vocabulary, math, and social skills.

According to Vygotsky, the teacher should participate in children's games within the classroom, guide children to solve problems in problem situations, encourage children to participate in activities both independently and with peers as well as be a model regarding appropriate behavior. In addition, the teacher should apply appropriate methods and techniques for children to learn. If these methods and techniques are not successful, he/she should change the children's attitude to learning, and as a result, change their learning outcomes in a positive direction (Kravtsova, 2017). Teachers should also enable children to regularly learn from and interact with each other (Stanulis \& Manning, 2002). Thus, a child can learn what he does not already know through their interactions with both the teacher and his/her peers and in doing so become more proficient in what he/she does know. Importantly, deficiencies in the physical environment may create problems regarding the implementation of curriculum, but the professional qualifications and competencies of teachers also play an important role in overcoming such inadequacies. Therefore, the inadequacy of learning environments can be improved through right practices as well as through appropriate adjustments introduced by teachers (Babaroğlu, 2018).

\section{Assessment of preschool education environment}

In this current study, a review of the related literature revealed a variety of standardized instruments developed to evaluate the adequacy of educational environments prepared for the education, development, and learning of children. One of these tools is Classroom Rating Scale (CRS) developed by Maxwell (2007), which is utilized to evaluate the physical environment of a classroom through six different aspects, namely social spaces, boundaries, privacy, personalization, complexity, 
scale, and adjacency. Maxwell (2007) developed this scale to find the possible relationship between the physical environment of a classroom and the cognitive competence of children. Also, Kvalitet I Dagtilbud - Quality in Preschool Scale (KIDS) developed by Kragh-Müller and Ringsmose (2015), is a scale established according to a Danish/Nordic cultural context, and is utilized to assess the quality of education and everyday practices in preschools by focusing on the areas of social relationships, physical environment as well as play and activities. In addition, the Classroom Practices Inventory (CPI) by Hyson, Hirsh-Pasek, and Rescorla (1990), is developed to measure reliable observations in the early childhood classroom in terms of curricular/activity focus and emotional climate. While, the Classroom Systems Observation Scale (CSOS), is a tool utilized to measure through observations, the functioning of classrooms from preschool education to the 6th grade. The CSOS consists of three dimensions including classroom cohesion (Emotional bonding, Supportiveness, Boundaries), classroom flexibility (Leadership, Discipline, Negotiation), and classroom communication (Listener's skills, Self-disclosure, Clarity). The Classroom Assessment Scoring System (CLASS) Pre-K by Pianta, La Paro and Hamre (2008), is also an observational instrument used to evaluate classroom quality from pre-kindergarten through the 3rd grade. This instrument consists of three areas including emotional support, classroom organization, and instructional support. In the Early Childhood Environment Rating Scale (Harms, Clifford, \& Cryer, 2005), an assessment through observation of the quality of early childhood environments is carried out. This scale is made up of six sub-scales which include space and furnishings, personal care routines, language and literacy, learning activities, interaction, and program structure. As a result, it is apparent that there have been many scales developed for assessing the preschool learning environment, yet these scales have been prepared according to different educational programs. Furthermore, it was determined that the scales utilized to assess the early childhood education environment in the Turkish literature had been adapted from foreign sources (Solak, 2007).

\section{Preschool education in Turkey and the Current Study}

The preschool education curriculum throughout Turkey was updated in 2013, and thus implemented in preschool education institutions across the country. Through the updated curriculum, the aim was to ensure that young children in Turkey are well-developed in all areas and are prepared for primary school as well as have quality educational environments that are consistent for all children including those in disadvantaged environments, and finally that all preschool students can speak Turkish in a correct and fluent manner. Thus, the curriculum is based on gains and indicators from the areas of cognitive, motor, language, social and emotional, and self-care development. In order for children to achieve gains in these areas, it is important for preschool education institutions and teachers to prepare a child-centered environment as well as activities which are rich in stimulation and are developmental, flexible, and play-based (MEB, 2013). In the study conducted by Özsırkıntı, Akay, and Y1lmaz Bolat (2014), it was concluded that the teachers included in the study evaluated the 2013 
MEB Preschool Education Curriculum as a student-centered, flexible and active learning program.

The curriculum incorporates an eclectic structure by encompassing different aspects of many programs in the world. The motivation for this is to establish the necessary learning environments for raising well-developed and productive individuals within the 21 st century. In the study carried out by Tuğluk and Özkan (2019), it is seen that the achievements of 21 st century skills in the field of social-emotional, cognitive and language development in the MEB 2013 Preschool Education Curriculum constitute $25.9 \%$ of the gains in the entire curriculum.

The curriculum should include attractive materials in learning centers such as blocks, dramatic play items, art supplies, books, science items, and things for music. Importantly, these materials should be prepared in line with gains and indicators which enrich children's learning experiences as well as meet their differing needs (MEB, 2013). Furthermore, it has been determined that these environments cannot be fully provided under the proper circumstances for all children when considering the general conditions of the country (Güçlü \& Altan, 2020; Kubanç, 2014; Karaküçük, 2008; Çobanoğlu, Yıldırım, \& Aydın, 2020). Since quality education should be carried out within suitable and quality environments, the adequacy of classroom environments in preschool education institutions should be evaluated in line with the objectives of the MEB 2013 Curriculum and ideal principles offered for establishing a quality classroom environment. The necessity of a measurement instrument that can evaluate the classroom environments in preschool education institutions in Turkey within the framework of the applied MEB 2013 Curriculum has emerged that overlaps with the Turkish culture and education structure. In addition, it has been observed that the preschool classroom environment is evaluated from an outside perspective through observations in the scales in the literature and adapted to Turkish culture. However, the evaluations of the teachers, who are the subjects of the class, in their field of expertise are important. The development of such an instrument will contribute to teachers' assessment of the quality of the classroom environment and making arrangements within the framework of the curriculum implemented to meet the needs of the children, so that children can benefit from the classroom environment better. In this direction, it was aimed by the researchers to develop the Early Childhood Classroom Environment Assessment Scale and to conduct a validity-reliability study.

\section{Method}

The research was carried out in the survey model, which is one of the quantitative research methods. The screening model involves identifying the specific characteristics of a group (such as abilities, attitudes, beliefs, and/or knowledge) or the group's views on a particular subject (Fraenkel \& Wallen, 2009). In this study, a survey model research was conducted to develop a valid and reliable measurement tool to evaluate the characteristics of the classroom environment in pre-school education institutions in Turkey. 


\section{Participants}

The study group of this research consists of 312 preschool teachers working in public and private kindergartens affiliated to the Ministry of National Education in the 2018-2019 academic year determined by maximum variation sampling. Maximum variation sampling involves selecting groups within the universe in which the subgroups are similar (Büyüköztürk, Kılıç Çakmak, Akgün, Karadeniz, \& Demirel, 2016). For this purpose, 312 preschool teachers who voluntarily participated in the evaluation of preschool classroom environments in seven different regions of Turkey were reached. The demographic information regarding the research group from this current study is included in Table 1.

Table 1. Demographic Data for The Sample

\begin{tabular}{|c|c|c|c|}
\hline Variables & Groups & $N$ & $\%$ \\
\hline \multirow{2}{*}{ Gender } & Female & 300 & 96.2 \\
\hline & Male & 12 & 3.8 \\
\hline \multicolumn{2}{|l|}{ Total } & 312 & 100 \\
\hline \multirow{4}{*}{ Age } & $20-30$ & 161 & 51.6 \\
\hline & $31-40$ & 102 & 32.7 \\
\hline & $41+$ & 40 & 12.8 \\
\hline & No response & 9 & 2.9 \\
\hline \multicolumn{2}{|l|}{ Total } & 312 & 100 \\
\hline \multirow{3}{*}{ Educational Status } & High school & 18 & 5.76 \\
\hline & University & 292 & 93.58 \\
\hline & No response & 2 & .06 \\
\hline \multicolumn{2}{|l|}{ Total } & 312 & 100 \\
\hline \multirow{3}{*}{ Year of Seniority } & 10 years or less & 220 & 70.5 \\
\hline & 11 years or above & 72 & 23.1 \\
\hline & No response & 20 & 6.4 \\
\hline \multicolumn{2}{|l|}{ Total } & 312 & 100 \\
\hline \multirow{8}{*}{ Region of Employment } & Mediterranean Region & 18 & 5.77 \\
\hline & Black Sea Region & 17 & 5.45 \\
\hline & Central Anatolia Region & 138 & 44.23 \\
\hline & Aegean Region & 32 & 10.26 \\
\hline & Eastern Anatolia Region & 33 & 10.58 \\
\hline & Southeastern Anatolia Region & 48 & 15.38 \\
\hline & Marmara Region & 16 & 5.13 \\
\hline & No response & 10 & 3.20 \\
\hline
\end{tabular}


10 D.E., Çakar, K.Z., Deniz, N. Teke, T. Baş, E. Kılınçcı \& N, Aksoy /Pamukkale University Journal of Education, 56, 1-34, 2022

\begin{tabular}{|c|c|c|c|}
\hline \multicolumn{2}{|l|}{ Total } & 312 & 100 \\
\hline \multirow{3}{*}{$\begin{array}{l}\text { Residence type for the region of } \\
\text { employment }\end{array}$} & City & 165 & 52.9 \\
\hline & Village/Town & 146 & 46.8 \\
\hline & No response & 1 & .3 \\
\hline \multicolumn{2}{|l|}{ Total } & 312 & 100 \\
\hline \multirow{2}{*}{ Type of Work Organization } & Public & 225 & 72.1 \\
\hline & Private & 87 & 27.9 \\
\hline \multicolumn{2}{|l|}{ Total } & 312 & 100 \\
\hline
\end{tabular}

When Table 1 is examined, it is seen that $96.2 \%$ of the study group consists of female and $3.8 \%$ male teachers, and $51.6 \%$ of these teachers are $20-30$ years old, $32.7 \%$ are between $31-40$ years old and $12.8 \%$ are 41 years old and over. $93.58 \%$ of the teachers are university graduates, $5.76 \%$ are high school graduates, $70.5 \%$ have 10 years or less and $23.1 \%$ have 11 years or more seniority years. $44.23 \%$ of the teachers are in the Central Anatolia Region, $15.39 \%$ in the Southeastern Anatolia Region, $10.58 \%$ in the Eastern Anatolia Region, $10.26 \%$ in the Aegean Region, $5.77 \%$ in the Mediterranean Region, \% 5.45 of them work in pre-school education institutions located in the Black Sea Region and 5.13\% in the Marmara Region. 52.9\% of the institutions where the teachers work are located in the city and $46.8 \%$ in the village/town. $72.1 \%$ of the institutions where teachers work are public and $27.9 \%$ are private pre-school education institutions.

\section{Steps taken to develop the data collection tool}

The eight steps indicated by DeVellis (2017) were utilized in the development of the measurement instrument for this current study. The steps were as follows:

(1) The relevant literature regarding aspects of classroom environment was reviewed, and the relevant measurement instruments including international curricula and approaches about preschool classroom environments were examined.

(2) In line with the construct of what the measurement instrument was aimed at measuring, the researchers visited five separate preschools and carried out observations regarding classroom environments. Next, an item pool was created in line with the information and observations obtained from the literature. While developing the scale items, the MEB Preschool Education Program, HighScope Approach, Socio-Cultural Development Theory, Social Learning Theory and Ecological Systems Theory were taken as basis.

(3) A 5-point Likert scale, with the options of Never (1), Rarely (2), Sometimes (3), Usually (4), and Always (5) was administered to teachers to assess their own classroom environments.

(4) The items were then submitted to experts to obtain their opinions regarding the item responses. At this stage, expert opinions were obtained from a preschool teacher, a lecturer with a 
D.E., Çakar, K.Z., Deniz, N. Teke, T. Baş, E. Kılınçcı \& N, Aksoy /Pamukkale University Journal of Education, 56, 1-34, 2022 11 $\mathrm{PhD}$ in Preschool Education, and a lecturer with research experience regarding classroom environments as well as a PhD in Measurement and Evaluation.

(5) In line with the feedback provided by the experts, the measurement instrument was revised, and a draft form was created which included 64-items.

(6) A pilot test was carried out by asking 103 preschool teachers to evaluate their classroom environment using the 64-item draft form. Through the piloting process, in addition to determining the average response time, the appropriateness of the measurement instrument items was determined in terms of legibility, intelligibility, confusing items for responders, and/or typographical errors. As a result, the necessary adjustments were made to items in the prepared measurement instrument with the creation of a corrected and finalized 66-item version of the Early Childhood Classroom Environment Assessment Scale (ECCEAS).

(7) The ECCEAS was administered to a total of 312 preschool teachers. In the validity studies of this scale, expert opinions regarding its content validity were consulted. For the construct validity, a Principal Components Analysis was conducted with data from 194 preschool teachers, and a Confirmatory Factor Analysis was conducted with data from 118 preschool teachers. In addition, for reliability studies of this scale, Cronbach alpha internal consistency coefficients were also calculated.

(8) The results of the analysis in this current study are discussed in detail within the findings section of this study.

\section{Data collection}

Before collecting data, the necessary permissions from the Turkish Ministry of National Education as well as approval from the Ethics Committee of Ankara University Social Sciences were obtained. To collect data in this study, the prepared scale was printed out on paper and tried to be delivered to preschool teachers working in kindergartens in all provinces of Turkey. In provinces that could not be reached through the mailed scales, the researchers provided an online version of the scale which was sent to preschool teachers in these cases. In the data collection process, 43 out of 81 cities from seven regions in Turkey (e.g., the Mediterranean, Black Sea, Aegean, Marmara, Central Anatolia, Eastern Anatolia, Southeastern Anatolia regions) were reached. As a result, participating preschool teachers evaluated their classroom environments in line with the scale items provided on the ECCEAS utilized in this study. In addition, through provided examples in trainings it was explained to the teachers how to utilize the measurement tool. Thus, after examining the explanations provided as well as the measurement tool, the teachers were then asked to rate their own classroom environments. 
12 D.E., Çakar, K.Z., Deniz, N. Teke, T. Baş, E. Kılınçcı \& N, Aksoy /Pamukkale University Journal of Education, 56, 1-34, 2022

\section{Data analysis}

The participating preschool teachers evaluated their own classroom environments which they provided to children by answering the 66-item ECCEAS. Then, the dataset was transferred to a computer and the data analysis process carried out. For the ECCEAS analysis, first, the principal components analysis was conducted, which was then followed by the confirmatory factor analysis. Importantly, factor analysis is utilized in theory development and/or testing as well as to understand the underlying structure of collected data (Tabachnick \& Fidell, 2015). The essential feature of the basic factor subtraction procedure is that each factor takes into account the maximum possible amount of variance of the factored variables (Gorsuch, 1974). Therefore, PCA was used to explain the most variance with the least variable. For the reliability analysis, the Cronbach alpha internal consistency reliability was calculated.

\section{Findings}

The scale items were numbered in a range of M1 - M66. To determine the validity of the scale (66 items) in this current study, principal components analysis, which is a form of exploratory analysis, was conducted. As the Kaiser Mayer Olkin (KMO) coefficient calculated in this analysis approached 1, the data was deemed suitable for analysis, while 1 signifies a perfect fit (Kalayc1, 2006). The fact that the KMO is higher than .60 and the Barlett Sphericity test is significant indicates that the data are suitable for factor analysis (Büyüköztürk, 2020). In factor analysis, Erkuş (2019) stated that according to the number of variables, the number of factors, etc., about the sample size. emphasizes that there are various opinions, but there is no definite agreed number or ratio. The KMO value for the data was higher than $.80(\mathrm{KMO}=.85)$, and the Bartlett test results $(\mathrm{X} 2=3469.901, \mathrm{DF}=703, \mathrm{p}$ $<0.05)$ were significant; therefore, a normal distribution was ensured, and the data was appropriate for PCA. The determinant coefficient (.009) was found to be greater than .00001 indicating that there was no problem regarding multicollinearity.

In addition, Horn's (1965) Parallel Analysis was utilized to decide the number of factors made for the scale. The SPSS and parallel analysis outputs were compared up to the sixth factor, and the sixth factor's eigenvalues in parallel analysis were found to be higher than the eigenvalues from the parallel analysis as well as the sixth factor's eigenvalues in the parallel analysis were found to be greater than the eigenvalues in SPSS, so the comparison was cut at the fifth factor. Thus, the scale was found to have a five-factor structure.

The Varimax vertical rotation technique was utilized as one of the vertical rotation techniques. According to Ho (2006), vertical rotation technique is used when the relationship between the factors is low (when the factors are independent).It was predicted that the relations between the factors would be low, and as a result of the analysis, the correlation levels between the five factors confirmed this situation (correlation values are between -0.376 and 0.202). Büyüköztürk 
(2020) also recommends vertical rotation to make the factors more specific.The purpose of rotation is to obtain interpretable, meaningful factors (Tabachnick \& Fidell, 2015). The items with eigenvalues lower than .30 and those showing overlaps $(1,2,3,4,5,6,7,8,15,18,26,28,30,31$, $32,33,34,35,36,37,38,47,54,58,63,64,65,66)$ were excluded from the analysis.

To decide how many factor structures the scale had, the eigenvalues of the factors were calculated in the analysis. As a result, the factors whose eigenvalue was found to be greater than 1 are presented in Table 2 .

Table 2. Factor Dependent on Eigenvalue Statistic and Percentage of Variance Explained

\section{Initial Eigenvalues}

\begin{tabular}{llll} 
& & $\begin{array}{l}\text { Explained } \\
\text { Variance } \\
\%\end{array}$ & $\begin{array}{l}\text { Total Explained Variance } \\
\%\end{array}$ \\
\hline 1 & Total & 25.707 & 25.707 \\
2 & 9.769 & 9.406 & 35.113 \\
3 & 3.574 & 7.050 & 42.162 \\
4 & 2.679 & 5.775 & 47.937 \\
5 & 2.194 & 4.191 & 52.128 \\
6 & 1.593 & 3.053 & 55.181 \\
7 & 1.160 & 2.874 & 58.055 \\
8 & 1.092 & 2.784 & 60.839 \\
\hline
\end{tabular}

As can be seen in Table 2, the scale had eight factors greater than its eigenvalue 1, indicating that the scale may consist of eight factors. But since there was no sharp decline after five factors, it was determined that it could be a five-factor scale.

The eigenvalue scree plot regarding the number of factors the scale had is provided in Figure 1.

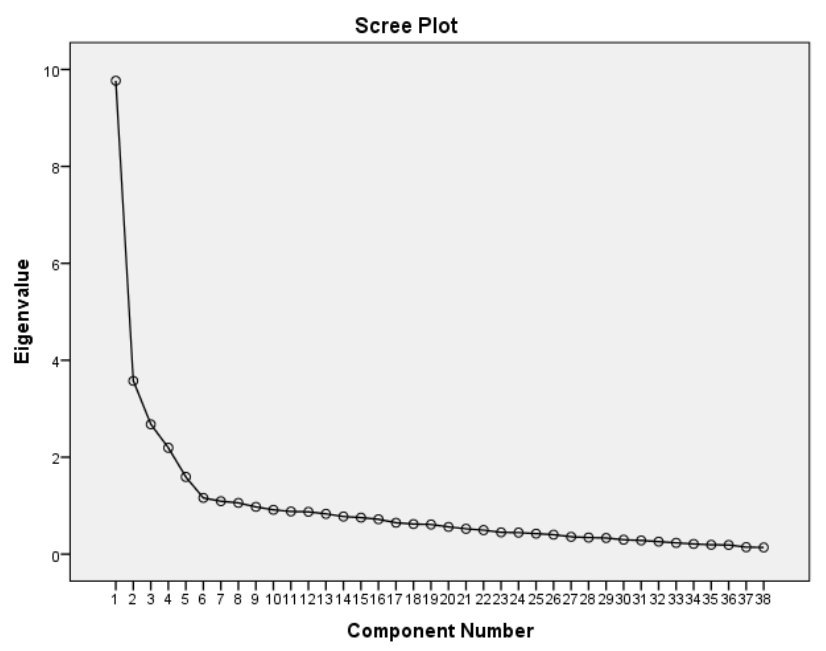

Figure 1. Factor Analysis Scree Plot 
14 D.E., Çakar, K.Z., Deniz, N. Teke, T. Baş, E. Kılınçc1 \& N, Aksoy /Pamukkale University Journal of Education, 56, 1-34, 2022

In Figure 1, the eigenvalue graph shows a break/curve at eight different points whose eigenvalue was greater than 1 . However, since there was no sharp decline after five factors in the chart, it was determined that the scale could be five factors. The item eigenvalues and factor loads determined through rotation of the items are provided in Table 3.

Table 3. Eigenvalues of Items, Factor Loads After Rotation and The Level of Variance Described

\begin{tabular}{|c|c|c|c|c|c|c|}
\hline Item & $\begin{array}{l}\text { Item } \\
\text { Eigenvalue }\end{array}$ & 1.Factor & 2.Factor & 3.Factor & 4.Factor 5.Factor & $\begin{array}{l}\text { Explained } \\
\text { Variance } \\
(\%)\end{array}$ \\
\hline I43 & .619 & .783 & & & & \\
\hline I41 & .637 & .783 & & & & \\
\hline $\mathrm{I} 42$ & .660 & .777 & & & & \\
\hline $\mathrm{I} 40$ & .623 & .722 & & & & \\
\hline I60 & .526 & .682 & & & & \\
\hline I44 & .506 & .646 & & & & 25.707 \\
\hline I59 & .534 & .646 & & & & \\
\hline I62 & .511 & .629 & & & & \\
\hline I61 & .505 & .615 & & & & \\
\hline I39 & .450 & .587 & & & & \\
\hline I53 & .312 & .479 & & & & \\
\hline $\mathrm{I} 23$ & .555 & & .703 & & & \\
\hline I14 & .515 & & .692 & & & \\
\hline I16 & .508 & & .688 & & & \\
\hline $\mathrm{I} 22$ & .504 & & .599 & & & \\
\hline I19 & .471 & & .589 & & & 9.406 \\
\hline $\mathrm{I} 20$ & .396 & & .578 & & & \\
\hline $\mathrm{I} 21$ & .467 & & .538 & & & \\
\hline I27 & .393 & & .505 & & & \\
\hline $\mathrm{I} 29$ & .384 & & .485 & & & \\
\hline I55 & .631 & & & .747 & & \\
\hline I56 & .600 & & & .720 & & \\
\hline I45 & .549 & & & .718 & & \\
\hline I46 & .527 & & & .701 & & 7.050 \\
\hline $\mathrm{I} 25$ & .437 & & & .650 & & \\
\hline I24 & .443 & & & .585 & & \\
\hline I57 & .394 & & & .562 & & \\
\hline
\end{tabular}


When Table 3 is examined, it is seen that the eigenvalues of the items are in the range of .312 - .660 and in this case, since the eigenvalues of the items were less than .30 , no items were removed. It was seen that there were 11 items $(43,41,42,40,60,44,59,62,61,39,53)$ in Factor 1 , and the factor loads of those items were between .479 and .783; Factor 2 had nine items $(23,14,16$, $22,19,20,21,27,29)$, and the factor loads of those items were in the range of .485 - .703; while there were seven items in Factor 3, $(55,56,45,46,25,24,57)$, and the factor loads of those items ranged from .562 to .747 ; Factor 4 had six items $(10,12,9,11,17,13)$, and the factor loads of those items ranged from .538 to .755 , while factor 5 had five items $(50,49,51,52$, 48), with the factor loads ranging from .538 to .755 . The scale was determined to consist of 38 items, and the first factor was found to explain for $25.71 \%$ of the total variance, the second factor $9.41 \%$, the third factor $7.05 \%$, the fourth factor $5.76 \%$, and the fifth factor $4.19 \%$; thus, $52.13 \%$ of the common variance was explained.

The first factor, which consisted of items that included the child's awareness of the problem, asking questions to produce solutions, discussing the solutions produced, and supporting the decision of a common solution, was named "Supporting problem solving". One of the items under this factor are provided in the following example.

39. I make the child realize the problem (For example, asking two children who have problems sharing toys questions like "What is the problem here? Can you explain the problem you are having?" and making them notice the problem in this way).

53. I involve children in the process of making decisions about the classroom (For example, ensuring that joint decisions are made with the children in cases where class rules are created, such as organizing learning centers or determining the number of students to study in the centers). 
16 D.E., Çakar, K.Z., Deniz, N. Teke, T. Baş, E. Kılınçcı \& N, Aksoy /Pamukkale University Journal of Education, 56, 1-34, 2022

The second factor included giving feedback to children regarding classroom rules and routines for using body language, materials, and/or verbally, which is exemplified by one item presented in the following under "Giving effective feedback".

14. I remind about the class rules using verbal expressions (For example, reminding a child who is running in the classroom of the class rule by saying "We walk around the classroom").

23. I give verbal feedback about negative behavior (For example, making statements like "If you're angry, you might say you don't like what your friend is doing instead of pushing them.").

Under the third factor, the items which contained negative expressions from teachers regarding the children's behavior regardless of children's individual differences and/or development levels were coded in reverse and named "Encouraging positive behaviors". The following example is provided to exemplify the items under this factor.

55. I use verbal expressions about gender (For example, telling a boy things like "A man does not cry", "You are a man, don't play with dolls", or telling a girl "You are a girl, don't play with repair tools").

57. I keep materials about gender roles (For example, keeping or using materials such as posters, books, toys that show their mothers doing housework and fathers doing repairs).

For the fourth factor it consisted of items that included preparing an appropriate physical classroom environment and materials for children, which was named "High-quality physical classroom environment". One example of items under this factor are as follows:

9. I keep enough materials in the learning centers (For example, keeping enough materials that allow several children to play together at the same time).

17. I use signs to remind them of the daily activity flow (For example, by studying the daily learning flow with children, using plot cards to have children follow the next step).

The fifth factor, which consisted of items that included supporting children's independent behavior, individual initiatives, leadership behavior, and the feeling of believing in success, was named "Supporting self-efficacy". The following item is provided as examples of this factor.

51. I support the children's public speaking/self-expression (For example, supporting practices such as telling a story, presenting products verbally, expressing feelings and thoughts about a subject, and introducing a material).

52. I make the children feel a sense of accomplishment (For example, giving a child roles and responsibilities appropriate to his/her developmental level to ensure that the child is successful).

A Confirmatory Factor Analysis was performed to test the 38-item five-factor structure of the scale which was determined through the Principal Component Analysis. The $t$ values regarding 
the explanation rates for the latent variables of the observed variables from the model as a result of the CFA which was performed to test the accuracy of the model fit within the scope of the construct validity of this scale are provided in Figure 2.

In Figure 2, the $t$ values regarding the relationship between the observed variables and latent variables from the five-factor model for the current scale are designated by the arrows. If the $t$ values were higher than 1.96, it was significant at the level of 0.05. Importantly, insignificant values should be excluded from analysis (Çokluk, Şekercioğlu, \& Büyüköztürk, 2014). As seen in Figure 2, the t values for the relationship between the observed variables and latent variables for the five-factor model varied between 2.10 - 11.06, and these values were significant at the 0.05 level, thus no items were excluded from the analysis. The standardized coefficients for error variances of the included items as well as the relationship between the latent and observed variables are provided in Figure 3.

As shown in Figure 3, it was determined that there were relationships varying from .42 to .74 between the first factor and its items, $.44-.85$ between the second factor and its items, $.21-.85$ between the third factor and its items, $.37-.89$ between the fourth factor and its items, and $.57-.83$ between the fifth factor and its items.

Next, $\chi^{2}=1096.19, \mathrm{sd}=655$ was revealed in the analysis. The $\chi 2 /$ sd ratio below 3 corresponds to a perfect fit (Kline, 2005). In this current study, an $\chi 2 / s d(1096.19 / 655)$ ratio was observed at 1.67, which demonstrates that the model data fit corresponded to the perfect fit.

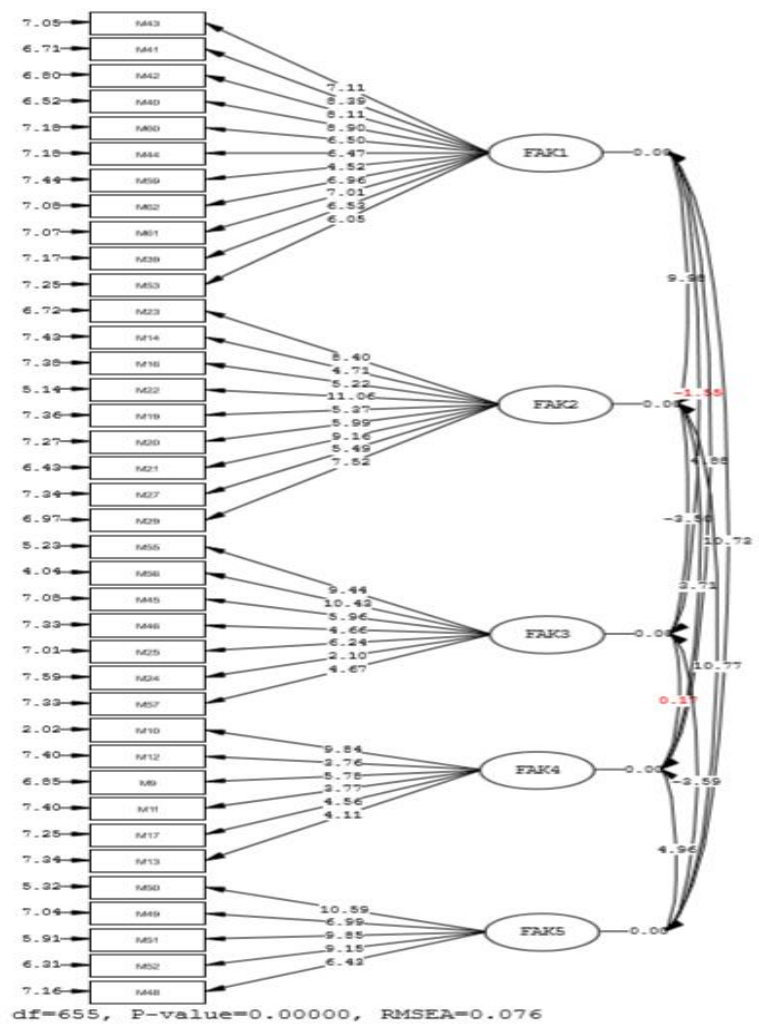

Figure 2. $t$ Values Regarding the Relationship Between Latent and Observed Variables 
18 D.E., Çakar, K.Z., Deniz, N. Teke, T. Baş, E. Kılınçcı \& N, Aksoy /Pamukkale University Journal of Education, 56, 1-34, 2022

The goodness of fit values regarding the result from the confirmatory factor analysis in this study are provided in Table 4.

Table 4. Goodness of Fit Values for the DFA

\begin{tabular}{llllllll}
\hline RMSEA & RMR & GFI & AGFI & NFI & NNFI & CFI & IFI \\
\hline .076 & .059 & .67 & .63 & .79 & .89 & .90 & .90 \\
\hline
\end{tabular}

When Table 4 was examined, it was seen that the fit indexes of RMSEA (.076) and S-RMR (.025) were below .05, providing a perfect fit (Jöreskog and Sörbom, 1993). As shown in Table 4, when the GFI, AGFI, NFI, NNFI, CFI, and IFI fit indices are examined, it can be seen that GFI = .67 , AGFI $=.63, \mathrm{NFI}=.79, \mathrm{NNFI}=.89, \mathrm{CFI}=.90$, and IFI $=.90$. When the GFI, AGFI, NFI, NNFI, CFI, and IFI are over .95 this means a perfect fit, and over .90 for these indices means a good fit (Tabachnick \& Fidell, 2015). In the case of this analysis, the GFI, AGFI, NFI values were observed to correspond with a weak fit, whereas the NNFI, CFI, and IFI corresponded to a good fit.

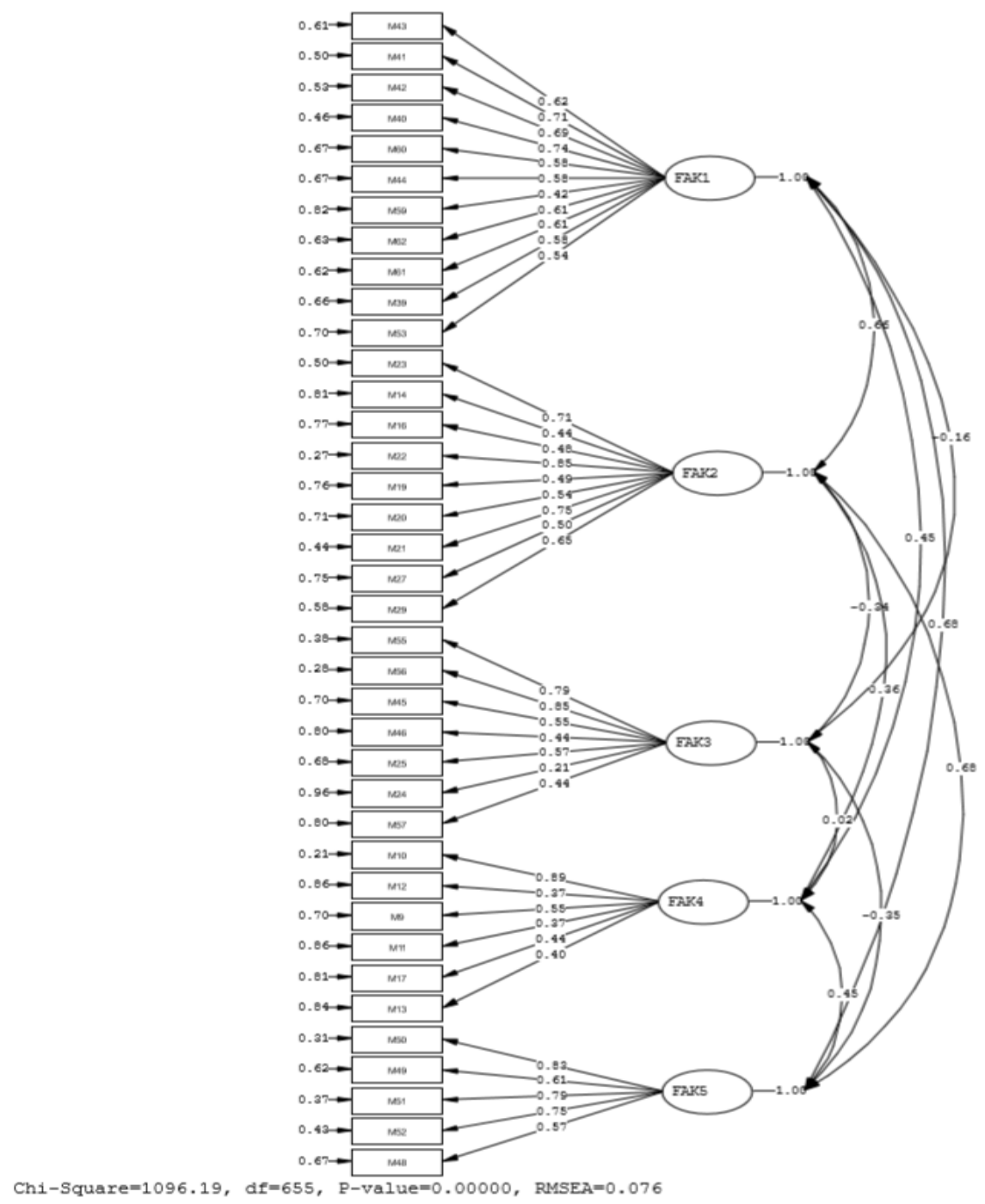

Figure 3. Standardized Coefficients Regarding the Relationship Between Latent and Observed Variables 
The Cronbach alpha internal consistency coefficients were also calculated as part of the reliability calculations in this analysis. The internal consistency coefficient was found to be .86 for the first factor (Supporting problem solving), .84 for the second factor (Giving effective feedback), .74 for the third factor (Encouraging positive behaviors), .66 for the fourth factor (High quality physical classroom environment), and .84 for the fifth factor (Supporting self-efficacy). When the values were examined, it was seen that the 4th Factor Cronbach's alpha coefficient was slightly below the expected lower limit of .70. This factor, which has high factor loading values, can be made stronger by increasing the number of items in future studies. As a result, it was concluded that the scale was found to be a reliable instrument (Kayış, 2016; Pallant, 2017). After the analyses, a valid and reliable scale was obtained, in which the analyzes could be performed on the sub-dimension scores.

\section{Discussion}

One of the most effective and safe ways to evaluate classroom settings is through standardized tools (Hui, Lee, Yeung, Chick, Ho, \& Ng, 2017). Therefore, the aim of the current study was to develop a valid and reliable measurement tool for evaluating the characteristics of early childhood classroom settings. To this end, a 66-item trial form was prepared and implemented with 312 preschool teachers throughout Turkey. As part of the validity analysis for the scale in this study, the opinions of experts were obtained regarding its content validity, as a result, Principal Components Analysis and Confirmatory Factor Analysis were performed to check for construct validity as well as the Cronbach alpha internal consistency coefficients were determined regarding its reliability. After conducting the analysis, a valid and reliable measuring instrument consisting of five factors and 38 items was finalized. Due to its compatibility with Turkish culture and the preschool education curriculum carried out in Turkey, the created measurement tool is expected to contribute to the literature. Furthermore, it is hoped the evaluation of the classroom environment in terms of both physical and social environment will benefit the field as it determines the strengths and weaknesses of the environments and paves the way for the arrangements to be made.

The factor structures of the developed scale in this study consist of five headings: 'Supporting problem solving', 'Providing effective feedback', 'Encouraging positive behaviors', 'High-quality physical classroom environment', and 'Supporting self-efficacy'. These factors and the items under each of these factors demonstrate parallelism with factors and items from other previously created measurement tools utilized for evaluating classroom environments, which represents the validity of the current scale. Importantly, even though there are similar factor structures under different names in other measurement tools (Fish, \& Dane, 2000; Harms, Clifford, \& Cryer, 2005; Kragh-Müller, \& Ringsmose, 2015; Maxwell, 2007; Pianta, La Paro, \& Hamre, 2008) and/or the similar items are grouped according to different factors, the underlying criteria put forward for evaluating classroom environments is the same. For example, under the 'Supporting 
20 D.E., Çakar, K.Z., Deniz, N. Teke, T. Baş, E. Kılınçcı \& N, Aksoy /Pamukkale University Journal of Education, 56, 1-34, 2022 problem solving' factor in the current measurement instrument, items such as supporting peer assistance in the process of problem solving, including those children in the process of making classroom decisions and/or providing an environment where different ideas are respected is previously described in a classroom environment assessment scale created by Fish and Dane (2000). This is done under the factors of 'classroom unity, classroom flexibility, and classroom communication' through the items of 'peers helping each other in the classroom', 'making decisions through teacher-children cooperation', and 'children expressing themselves freely'. Importantly, by providing opportunities for children to express themselves and prepare an environment where different opinions are respected is an example of a high-quality psycho-social environment which includes encouraging, clear, and welcoming characteristics (Havu-Nuutinen \& Niikko, 2014). Due to this situation, supporting children in organizing tasks required to perform an activity/performance were examined under this factor, which is important for his/her exploration and learning skills and is among the primary objectives of a learning environment (Vosniadou, Ioannides, Dimitrakopoulou, \& Papademetriou, 2001). Furthermore, Ocak (2010) states that for children to have the ability to consider a variety of solutions in different areas, teachers should guide and support children in having this perspective through the process of appropriate education and modeling. In a measurement instrument adapted by Solak (2007), teachers providing support to children in solving the students' problems is examined under the category of discipline. In the measurement instrument developed in this current study, according to the factor of 'Supporting problem solving', a variety of support strategies such as making children aware of a problem, trying to solve problems by asking questions, giving hints, discussing and applying solutions were discussed.

The factor of 'Giving effective feedback' has been examined as an item according to various factor structures in several other measurement tools. For example, in a measurement tool developed by Reddy, Fabiano and Dudek (2013), it is considered as a factor and teachers provide feedback by using verbal or non-verbal expressions or other gestures for denoting positive or negative behaviors, as a result, how the teachers supported the children's learning through their answers was examined. Furthermore, in another study Hancock and Carter (2016), mention the status of approving appropriate behavior and providing feedback according to the factor of consistently responding to problematic behavior through the measurement tool they created. Whereas in the current study, verbal feedback regarding positive and negative behaviors, providing feedback by using body language and/or physical contact as well as giving feedback by expressing children's feelings were discussed in detail under the factor of 'Giving effective feedback'.

The situations of not giving activity above or below the child's development and not giving feedback to support competition between children were examined under the factor of 'Encouraging positive behaviors'. They were discussed as factors in the form of the ease-difficulty level of tasks assigned to children and the competitive environment within the classroom in the My Class 
Inventory developed by Fraser and Fisher (1982). Importantly, providing children with experiences appropriate to their development level also ensures that they realize their abilities and do not experience a sense of inadequacy (Bandura, 1989). While avoiding comparing children is important in supporting cooperation (Senemoğlu, 2015), it is one of the factors that should be considered when providing an effective classroom environment. In addition, verbal expressions of teachers, activities, and/or materials are not analyzed by considering gender in other measurement tools due to the common knowledge that these practices may create false gender stereotypes and gender norms in children (Aina \& Cameron, 2011) as well as shape their interests and skills (Wolter, Braun, \& Hannover, 2015).

In this study, "high-quality physical classroom environment" is one of the factors and consists of many items that are in parallel with the measurement tools developed previously. For example, the availability of an adequate number of materials as well as a variety of materials to support different play experiences that reflect family lives of children discussed in the current study was included in another measurement tool (Classroom Practices Inventory) developed by Hyson, Hirsh-Pasek, and Rescorla (1990) as creating classroom learning centers such as dramatic games, blocks, science, mathematics, books, art, and music and having an adequate amount of diverse materials within classroom learning centers that support children's daily life experiences. Furthermore, in a measurement instrument developed by Siwatu, Putman, Starker-Glass and Lewis (2015), they do a detailed analysis of several factors such as using materials that reflect children's family life (e.g., children's own culture), knowing and respecting children's culture as well as using children's culture within the classroom and preparing an effective classroom environment. Also, it is important to remind children of the classroom rules by using materials and reminder signs for the flow of daily activities, which are evaluated according to this factor as well as under the factor of "creating a predictable and organized classroom environment to support positive behavior" in the measurement tool developed by Hancock and Carter (2016). In addition, the physical-aesthetic environment dimension is defined by Havu-Nuutinen and Niikko (2014) as one of the three primary dimensions of the preschool learning environment and stresses the importance of an environment built with natural materials, and as a result, this criterion is included as an item in the developed scale. In other words, items under this factor are grouped under similar or different factor structures in a variety of other measurement tools, and although they are viewed as important in most measurement tools in terms of evaluating the classroom environment, they are used in this case for defining the physical environment.

According to Kragh-Müller and Ringsmose (2015), one of the primary factors determining the quality of a classroom environment is the support provided by the environment regarding children's self-confidence and/or social competence. This was discussed under the final factor of the current scale developed, 'Supporting self-efficacy', and according to this factor, the teacher was expected to 
22 D.E., Çakar, K.Z., Deniz, N. Teke, T. Baş, E. Kılınçcı \& N, Aksoy /Pamukkale University Journal of Education, 56, 1-34, 2022 create a suitable environment for the child that supports the leadership skills of children as well as allows them to experience a sense of achievement through their actions and activities. In addition, under this factor, there were items such as the ability of children to freely choose their own activities, behave independently, and do individual learning. These items are also included in a measurement tool developed by Hyson, Hirsh-Pasek and Rescorla (1990) for evaluating the early childhood classroom environment. Furthermore, supporting children to be confident enough to speak in public and express himself/herself is considered as the factor 'encouraging children to speak' seen in the measurement tool developed by Phillips, Zhao and Weekley (2018). This factor is seen as important for children because it plays a part in their language skills development. Overall, the "Supporting self-efficacy" factor or the items under this factor were considered as a common criterion for evaluating the classroom environment.

\section{Conclusions}

As a result, the factor structures and items of the created measurement tool appeared to be compatible with the factor structures and items of many measurement tools used to evaluate classroom environments. Also, the analysis results found in this current study provided sufficient evidence that the ECCEAS is a valid and reliable measurement instrument.

\section{Limitations}

This study was limited to data obtained from preschool teachers working in State and private schools operated under the Turkish Ministry of National Education (MoNE) and located within 43 provinces throughout Turkey. In addition, the data were only obtained between the years of 2018 to 2019 . Therefore, it is necessary to consider possible changes within the schools and/or among teachers over the time that has elapsed since this current study was carried out.

\section{Recommendations}

In this current study the researchers were able to contact and implement the study within schools located in 43 provinces throughout Turkey. It is suggested that further reliability tests be performed by including more provinces from within the current country of study as well as expanding future studies by increasing the diversity of provinces and schools from within the region. Furthermore, in future studies, tools can be developed to evaluate the classroom environments of different grade levels as well as carry out similar intercultural studies to evaluate these learning environments within different countries. Using the developed measurement tool and the existing measurement tools to evaluate the preschool classroom environment (scales containing observation) can make evaluations involving multiple perspectives. Interventions can be made in assessing and organizing classroom environments by considering the long-term effects of the classroom environment provided to children in the preschool period. Similarly, it can be used as a tool to evaluate and improve existing classroom environments in the development of early childhood education policies. 
Ethical Approval: This research was conducted with the permission of Ankara University Social Sciences Sub-Ethics Committee with the decision dated 30/04/2018 and numbered 6/91.

Conflict Interest: The authors declared no potential conflicts of interest with respect to the research, authorship, and/or publication of this article.

Authors Contributions: The authors declare that they have contributed equally to the article.

\section{References}

Aina, O. E., \& Cameron, P. A. (2011). Why does gender matter? Counteracting stereotypes with young children. Dimensions of Early Childhood, 39(3), 11-20. Retrieved from https://eric.ed.gov/?id=EJ945697

Aktulun, Ö. U., \& Kiziltepe, G. I. (2018). Using learning centers to improve the language and academic skills of preschool children. World Journal of Education, 8(6), 32-44. https://doi.org/10.5430/wje.v8n6p32.

Arıkan, A. (2016). Highscope programı [Highscope program]. F. Temel (Ed.). Erken çocukluk eğitiminde yaklaşımlar ve programlar [Early childhood education approaches and programs]. Ankara: Vize Publishing.

Azlina, W., \& Zulkiflee, A. S. (2012). A pilot study: The impact of outdoor play spaces on kindergarten children. Procedia-Social and Behavioral Sciences, 38, 275-283. https://doi.org/10.1016/j.sbspro.2012.03.349.

Babaroğlu, A. (2018). Eğitim ortamları açısından okul öncesi eğitim kurumları [Pre-school education institutions in terms of educational environments]. Abant İzzet Baysal Üniversitesi Eğitim Fakültesi Dergisi [Abant İzet Baysal University Journal of the Faculty of Education], 18(3), 1313-1330. https://doi.org/10.17240/aibuefd.2018.18.39790-471118

Bandura, A. (1977). Social learning theory. London: Prentice Hall.

Bandura, A. (1989). Human agency in social cognitive theory. American Psychologist, 44(9), 11751189. https://doi.org/10.1037/0003-066X.44.9.1175

Bandura, A. (1995). Self-Efficacy in changing societies. A. Bandura (Ed.). Exercise of personal and collective efficacy in changing societies (pp. 1-45). Cambridge: Cambridge University Press.

Belfield, C., Nores, M., Barnett, W. S., \& Schweinhart L. (2005). Updating the economic impacts of the High/Scope Perry Preschool Program. Educational Evaluation and Policy Analysis, 27(3), 245-262. https://doi.org/10.3102/01623737027003245 
24 D.E., Çakar, K.Z., Deniz, N. Teke, T. Baş, E. Kılınçcı \& N, Aksoy /Pamukkale University Journal of Education, 56, 1-34, 2022

Bjorklund, D. F., \& Causey, K. B. (2017). Children's thinking: Cognitive development and individual differences. Sage Publications.

Bodrova, E., \& Leong, D. J. (2017). Zihnin araçları: Erken çocukluk eğitiminde Vygotsky yaklaşımı [Means of the mind: Vygotsky approach to early childhood education]. (G. Haktanır, Trans. Eds; T. Güler, F. Şahin, A. Yılmaz, E. Kalkan, Trans.) Ankara: Anı Publishing (1996).

Botsoglou, K., Beazidou, E., Kougioumtzidou, E., \& Vlachou, M. (2019). Listening to children: using the ECERS-R and Mosaic approach to improve learning environments: A case study. Early Child Development and Care, 189(4), 635-649. https://doi.org/10.1080/03004430.2017.1337006

Brodin, J., \& Renblad, K. (2019). Improvement of preschool children's speech and language skills. Early Child Development and Care, 1-9. https://doi.org/10.1080/03004430.2018.1564917

Broekhuizen, M. L., Mokrova, I. L., Burchinal, M. R., Garrett-Peters, P. T., \& Family Life Project Key Investigators. (2016). Classroom quality at pre-kindergarten and kindergarten and children's social skills and behavior problems. Early Childhood Research Quarterly, 36, 212-222. https://doi.org/10.1016/j.ecresq.2016.01.005

Bronfenbrenner, U. (1976). The Experimental ecology of education. Educational Researcher, 5(9), 5-15. https://doi.org/10.3102/0013189X005009005

Bronfenbrenner, U. (1994). Ecological models of human development. In P. Peterson, E. Baker, \& B. McGaw (Eds.). International Encyclopedia of Education (2nd Ed.), (Vol. 3. pp. 1643-7) Oxford: Elsevier.

Büyüköztürk, Ş. (2020). Sosyal bilimler için veri analizi el kitabı [Manual of data analysis for social sciences] (28th Edition). Ankara: Pegem Academy.

Büyüköztürk, Ş., Çakmak, E. K., Akgün, Ö. E., Karadeniz, Ş. \& Demirel, F. (2016). Bilimsel araştırma yöntemleri [Scientific research methods]. Ankara: Pegem Academy.

Che Ahmad, C. N., \& Amirul, N. J. (2017). The effect of the physical learning environment on students' health, enjoyment, and learning. Jurnal Pendidikan Sains dan Matematik Malaysia (JPSMM UPSI), 7(1), 47-55. https://doi.org/10.37134/jpsmm.vol7.no1.4.2017

Choi, H. H., Van Merriënboer, J. J., \& Paas, F. (2014). Effects of the physical environment on cognitive load and learning: Towards a new model of cognitive load. Educational Psychology Review, 26(2), 225-244. https://doi.org/10.1007/s10648-014-9262-6.

Çobanoğlu, R., Yıldırım, A., \& Aydın, Y. Ç. (2020). Okul öncesi eğitimin niteliğine bir bakış: Aileler, öğretmenler ve çalışma koşulları ile ilgili sorunlar [Quality of early childhood education at a glance: Problems related to families, teachers, and working conditions]. 
Eğitimde Nitel Araştırmalar Dergisi [Journal of Qualitative Research in Education], 8(2), 407-430. https://doi.org/10.14689/issn.2148-624.1.8c.2s.1m

Çokluk, Ö., Şekercioğlu G., \& Büyüköztürk Ş. (2014). Sosyal bilimler için çok değişkenli istatistik SPSS ve LISREL uygulamaları [Multivariate statistics SPSS and LISREL applications for social sciences]. Ankara: Pegem Publishing.

Demiriz, S., Karadag, A., \& Ulutas, I. (2003). Educational environment and equipment in preschool education institutions. Ankara: Ani Publishing.

DeVellis, R. F. (2017). Ölçek geliştirme: Kuram ve uygulamalar [Scale development: Theory and practices]. (T. Totan, Trans.). Ankara: Nobel Publishing (2012).

Epstein, A. S., \& Schweinhart, L. J. (2018). Educational tenets of the HighScope curriculum. In M. Fleer \& B. van Oers (Eds.). International Handbook of Early Childhood Education (Vol 1, pp. 1347-1377). The Netherlands: Springer.

Erdiller, Z. B. (2010). Erken çocukluk eğitiminde temel kuram ve yaklaşımlar. [Basic theories and approaches in early childhood education]. İ. H. Diken (Ed.). Erken çocukluk eğitimi [Early childhood education] (pp. 56-90). Ankara: Pegem Publishing.

Erkuş, A. (2019). Psikolojide ölçme ve ölçek geliştirme-I: Temel kavramlar ve işlemler [Measurement and scale development in psychology-I: Basic concepts and processes] (4th Ed.). Ankara: Pegem Publishing.

Fish, M. C., \& Dane, E. (2000). The classroom systems observation scale: Development of an instrument to assess classrooms using a systems perspective. Learning Environments Research, 3(1), 67-92. https://doi.org/10.1023/A:1009979122896

Fraenkel, J. R. \& Wallen, N. E. (2009). How to design and evaluate research in education. New York: McGraw Hall.

Fraser, B. J., \& Fisher, D. L. (1982). Evaluation studies: predictive validity of My Class Inventory. Studies in Educational Evaluation, 8, 129-140. https://doi.org/10.1016/0191491X(82)90004-9

Gagnon, S. G., Kidder-Ashley, P., \& Nickerson, A. B. (2017). Assessment of school and classroom environment. In B. Bracken \& R. Nagle (Eds). Psychoeducational assessment of preschool children (pp. 173-194). USA: Routledge.

Goble, P., Hanish, L. D., Martin, C. L., Eggum-Wilkens, N. D., Foster, S. A., \& Fabes, R. A. (2016). Preschool contexts and teacher interactions: Relations with school readiness. Early Education and Development, 27(5), 623-641. https://doi.org/10.1080/10409289.2016.1111674. 
26 D.E., Çakar, K.Z., Deniz, N. Teke, T. Baş, E. Kılınçcı \& N, Aksoy /Pamukkale University Journal of Education, 56, 1-34, 2022

Gorsuch, R. L. (1983). Factor analysis (2nd Ed.). Hillsdale, NJ: Lawrence Erlbaum Associates.

Güçlü, M., \& Altan, A. E. (2020). Türkiye'de okul öncesi eğitim alanında görülen sorunlar üzerine genel bir değerlendirme [An overall assessment on the problems of preschool education in Turkey]. Uluslararası Sosyal Araştırmalar Dergisi [The Journal of International Social Research], 13(69), 1051-1061. https://doi.org/10.17719/jisr.2020.4019.

Gültekin Akduman, G. (2012). Okul öncesi eğitim tanımı ve önemi [Definition and importance of pre-school education]. G. Uyanık Balat (Ed.). Okul öncesi eğitime giriş [Introduction to preschool education], (pp. 2-15). Ankara: Pegem Academy.

Hancock, C. L., \& Carter, D. R. (2016). Building environments that encourage positive behavior. Young Children, 71(1), 68-73. Retrieved from https://scholarworks.boisestate.edu/sped_facpubs/111/

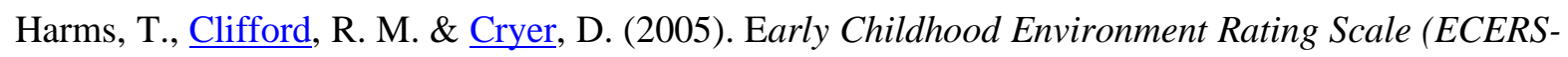
R): Revised edition. New York: Teachers College Press

Havu-Nuutinen, S., \& Niikko, A. (2014). Finnish primary school as a learning environment for sixyear-old preschool children. European Early Childhood Education Research Journal, 22(5), 621-636. https://doi.org/10.1080/1350293X.2014.969084.

Ho, R. (2006). Handbook of univariate and multivariate data analysis and interpretation with SPSS. Boca Raton: CRS Press.

Hohmann, M., \& Weikart, D. P. (2000). Küçük çocukların eğitimi [Education of young children]. (S. Saltiel Kohen \& Ü. Öğüt, Trans. Eds). İstanbul: Hisar Education Foundation. (1995).

Holt, N. (2010). Bringing the High Scope approach to your early years practice. USA: Routledge.

Horn, J. L. (1965). A rationale and test for the number of factors in factor analysis. Psychometrica, 30(2), 179-185. Retrieved from https://link.springer.com/article/10.1007/BF02289447

Hui, A. N., Lee, M. L., Yeung, P. S., Chick, J. H., Ho, A. K., \& Ng, C. K. (2017). Enhancement of quality in early childhood education: Using the Early Childhood Environment Rating ScaleExtension (ECERS-E) and Revised (ECRES-R) as formative assessment tools for professional development-an experience from Hong Kong. Asia-Pacific Journal of Research in Early Childhood Education, 11(3), 1-16. https://doi.org/10.17206/APJRECE.2017.11.3.1.

Hyson, M. C., Hirsh-Pasek, K., \& Rescorla, L. (1990). The classroom practices inventory: An observation instrument based on NAEYC's guidelines for developmentally appropriate practices for 4-and 5-year-old children. Early Childhood Research Quarterly, 5(4), 475-494. https://doi.org/10.1016/0885-2006(90)90015-S. 
Jöreskog, K. G., \& Sörbom, D. (1993). LISREL 8: Structural equation modeling with the SIMPLIS command language. Lincolnwood: Scientific Software International.

Kalaycı, Ş. (2006). SPSS uygulamalı çok değişkenli istatistik teknikleri. [SPSS applied multivariate statistical techniques]. Ankara: Asil Yayınları.

Karaküçük, S. A. (2008). Okul öncesi eğitim kurumlarında fiziksel/mekansal koşulların incelenmesi: Sivas ili örneği [A study on physical / spatial conditions of the preschool education centers : In Sivas]. Cumhuriyet Üniversitesi Edebiyat Fakültesi Sosyal Bilimler Dergisi/Cumhuriyet University Faculty of Letters Journal of Social Sciences, 32(2), 307-320. Retrieved from http://eskidergi.cumhuriyet.edu.tr/makale/1843.pdf.

Kayış A. (2016). Güvenirlik analizi [Reliability analysis]. Ş Kalaycı (Ed.), SPSS uygulamalı çok değişkenli istatistik teknikleri [SPSS applied multivariate statistical techniques]. Ankara: Asil Yayınları.

Kline, R. B. (2005). Principles and practice of structural equation modeling. New York: Guilford Publications.

Knauf, H. (2019). Physical environments of early childhood education centres: Facilitating and inhibiting factors supporting children's participation. International Journal of Early Childhood, 51(3), 355-372. https://doi.org/10.1007/s13158-019-00254-3

Kostelnik, M. J., Soderman, A. K., Whiren, A. P., \& Rupiper, M. L. (2015). Developmentally appropriate curriculum: Best practices in early childhood education (6th ed.). Upper Saddle River, NJ: Prentice Hall.

Kragh-Müller, G., \& Ringsmose, C. (2015). Educational quality in preschool centers. Childhood Education, 91(3), 198-205. https://doi.org/10.1080/00094056.2015.1047311.

Kravtsova, E. (2017). The sense and the meaning of cultural-historical theory of L. S. Vygotsky. CRI-SAS International Journal: Vygotsky's Heritage: Innovation in Education, 4(1), 35-47. https://doi.org/10.51657/ric.v4i1.40991

Kubanç, Y. (2014). Okul öncesi eğitim kurumlarının fiziki durumunun incelenmesi [Physical examination of the state of preschool education institutions]. Journal of International Social $\begin{array}{llll}\text { Research, } & 7(31), & \text { 675-688. } & \text { Retrieved }\end{array}$ https://eds.p.ebscohost.com/eds/pdfviewer/pdfviewer?vid=0\&sid=e966131a-7049-4de88a2c-43075a91a595\%40redis.

Lim, P. P. L., \& Bahauddin, A. (2019). Factors for consideration to achieve a contextually appropriate physical environment in Malaysian preschools. International Journal of Early Years Education, 27(4), 391-408. https://doi.org/10.1080/09669760.2018.1507903. 
28 D.E., Çakar, K.Z., Deniz, N. Teke, T. Baş, E. Kılınçcı \& N, Aksoy /Pamukkale University Journal of Education, 56, 1-34, 2022

Lorsbach, A., \& Jinks, J. (1999). Self-efficacy theory and learning environment research. Learning Environments Research, 2(2), 157-167. https://doi.org/10.1023/A:1009902810926

Mashburn, A. J., Pianta, R. C., Hamre, B. K., Downer, J. T., Barbarin, O. A., Bryant, D., ... \& Howes, C. (2008). Measures of classroom quality in prekindergarten and children's development of academic, language, and social skills. Child Development, 79(3), 732-749. https://doi.org/10.1111/j.1467-8624.2008.01154.x.

Maxwell, L. E. (2007). Competency in childcare settings: The role of the physical environment. Environment and Behavior, 39(2), 229-245. https://doi.org/10.1177/0013916506289976

McGurk, H. (2017). Issues in childhood social development. USA: Routledge.

MEB. (2013). Milli Ĕgitim Bakanlı̆̆l okul öncesi eğitim programı. [Ministry of National Education Preschool education program]. Retrieved from https://ttkb.meb.gov.tr/www/ogretimprogramlari/icerik/72

Mohamed, A. H. H., \& Marzouk, S. A. F. M. (2016). The association between preschool classroom quality and children's social-emotional problems. Early Child Development and Care, 186(8), 1302-1315. https://doi.org/10.1080/03004430.2015.1092140

Obaki, S. O. (2017). Impact of classroom environment on children's social behavior. International Journal of Education and Practice, 5(1), 1-7. https://doi.org/10.18488/journal.61/2017.5.1/61.1.1.7

Ocak, S. (2010). The effects of child-teacher relationships on interpersonal problem-solving skills of children. Infants \& Young Children, 23(4), 312-322. https://doi.org/10.1097/IYC.0b013e3181f27769

Özgün, Ö. (2015). Her yönüyle okul öncesi eğitim [The magic years of life: Preschool]. In F. Turan and A. İ. Yükselen (Eds.). Çocuk gelişimi kuramları[Child development theories] (pp. 4682). Ankara: Hedef Publishing.

Ozkal, K., Tekkaya, C., Cakiroglu, J., \& Sungur, S. (2009). A conceptual model of relationships among constructivist learning environment perceptions, epistemological beliefs, and learning approaches. Learning and Individual Differences, 19(1), 71-79. https://doi.org/10.1016/j.lindif.2008.05.005.

Özsırkıntı, D., Akay., C. \& Y1lmaz Bolat, E. (2014). Okul öncesi öğretmenlerinin okul öncesi eğitim programı hakkındaki görüşleri adana ili örneği. [The opinions of preschool teachers concerning preschool education programme (Adana sample)] Ahi Evran Üniversitesi Kırşehir Eğitim Fakültesi Dergisi [Journal of Ahi Evran University Kirsehir Education Faculty], 15(1), 313-331. Retrieved from https://dergipark.org.tr/tr/pub/kefad/issue/59467/854538 
Pallant, J. (2017). SPSS kullanma kılavuzu SPSS ile adım adım veri analizi [SPSS user manual Stepby-step data analysis with SPSS]. (S. Balcı \& B. Ahi, Trans.). Ankara: Anı Publishing.

Parshekofti, N. S. (2014). Studying the effect of physical space of learning environment on students' academic achievement motive: (Case study: Payam-e-Nour University, Qeshm International Branch). International Journal of Academic Research in Business and Social Sciences, 4(7), 111. https://doi.org/10.6007/IJARBSS/V4-I7/994.

Phillips, B. M., Zhao, Y., \& Weekley, M. J. (2018). Teacher language in the preschool classroom: Initial validation of a classroom environment observation tool. Early Education and Development, 29(3), 379-397. https://doi.org/10.1080/10409289.2017.1408371.

Pianta, R. C., La Paro, K. M., \& Hamre, B. K. (2008). Classroom Assessment Scoring System: Manual K-3. London: Paul H Brookes Publishing.

Reddy, L. A., Fabiano, G. A., \& Dudek, C. M. (2013). Concurrent validity of the classroom strategies scale for elementary School-Observer Form. Journal of Psychoeducational Assessment, 31(3), 258-270. https://doi.org/10.1177/0734282912462829.

Roeser, R. W., Midgley, C., \& Urdan, T. C. (1996). Perceptions of the school psychological environment and early adolescents' psychological and behavioral functioning in school: The mediating role of goals and belonging. Journal of Educational Psychology, 88(3), 408. https://doi.org/10.1037/0022-0663.88.3.408.

Şahin, S. (2010). 0 - 6 yaş arası çocukların temel gelişimsel özellikleri: fiziksel ve sosyal- duygusal gelişim [Basic developmental characteristics of children aged 0-6: physical and socialemotional development]. In İ. Diken (Ed.). Erken çocukluk eğitimi [Early childhood education] (pp. 92-133). Ankara: Pegem Publishing.

Sandberg, G. (2017). Different children's perspectives on their learning environment. European Journal of Special Needs Education, 32(2), 191-203. https://doi.org/10.1080/08856257.2016.1216633.

Senemoğlu, N. (2015). Gelişim, ögrenme ve ögrretim kuramdan uygulamaya. [Development, learning and teaching from theory to practice]. Ankara: Yarg1 Academy Publishing.

Shaari, M. F., \& Ahmad, S. S. (2016). Physical learning environment: Impact on children school readiness in Malaysian preschools. Procedia-Social and Behavioral Sciences, 222, 9-18. https://doi.org/10.1016/j.sbspro.2016.05.164.

Sheridan, S., \& Pramling Samuelsson, I. (2013). Preschool a source for young children's learning and well-being. International Journal of Early Years Education, 21(2-3), 207-222. https://doi.org/10.1080/09669760.2013.832948. 
30 D.E., Çakar, K.Z., Deniz, N. Teke, T. Baş, E. Kılınçcı \& N, Aksoy /Pamukkale University Journal of Education, 56, 1-34, 2022

Siwatu, K. O., Putman, S. M., Starker-Glass, T. V., \& Lewis, C. W. (2015). The Culturally Responsive Classroom Management Self-Efficacy Scale: Development and initial validation. Urban Education, 1-27. https://doi.org/10.1177/0042085915602534.

Solak, N. (2007). Adana il merkezinde bulunan okulöncesi eğitim kurumlarında kalitenin incelenmesi [Examination of quality in pre-school education institutions in Adana city center]. (Unpublished master dissertation). Çukurova Üniversitesi Sosyal Bilimleri Enstitüsü, Adana.

Spencer, C. J. (2006). Children and their environments: Learning, using, and designing spaces. USA: Cambridge University Press.

Stanulis, R. N., \& Manning, B. H. (2002). The teacher's role in creating a positive verbal and nonverbal environment in the early childhood classroom. Early Childhood Education Journal, 30(1), 3-8. https://doi.org/10.1023/A:1016581612865

Tabachnick, B. G., \& Fidell, L. S. (2015). Using multivariate statistics. (M. Baloğlu, Trans.). Ankara: Nobel Publishing.

Tadjic, M., Martinec, M., \& Farago, A. (2017). The impact of physical settings on pre-schoolers classroom organization. European Journal of Education Studies, 1(1), 14-36. http://dx.doi.org/10.46827/ejes.v0i0.2.

Trawick-Smith, J. (2014). Erken çocukluk döneminde gelişim: Çok kültürlü bir baklş açısı [Early childhood development: A multicultural perspective]. (B. Akman, Trans.). Ankara: Nobel Publishing.

Tuğluk, M. N., \& Özkan, B. (2019). MEB 2013 okul öncesi eğitim programının 21. Yüzyıl becerileri açısından analizi [Analysis of MoNE 2013 Preschool Education Program in terms of 21st Century Skills]. Journal of Primary Education, 1(4), 29-38. Retrieved from https://dergipark.org.tr/tr/pub/temelegitim/issue/49907/634024

Vosniadou, S., Ioannides, I., Dimitrakopoulou, A., \& Papademetriou, E. (2001). Designing learning environments to promote conceptual change in science. Learning and Instruction, 11, 381419. https://doi.org/10.1016/S0959-4752(00)00038-4.

Vygotsky, L. S. (1978). Mind in society: The development of higher psychological processes (M. Cole \& S. Scribner, Trans. Eds.). London: Harvard University Press.

Weinstein, C. S. (1979). The physical environment of the school: A review of the research. Review of Educational Research, 49(4), 577-610. https://doi.org/10.3102/00346543049004577.

Wilson, B. G. (1996). Constructivist learning environments: Case studies in instructional design. USA: U.S.A. Educational Technology Publication. 
Wiltshire, M. (2018). Understanding the High Scope Approach: Early years education in practice. USA: Routledge.

Wolter, I., Braun, E., \& Hannover, B. (2015). Reading is for girls!? The negative impact of preschool teachers' traditional gender role attitudes on boys' reading related motivation and skills. Frontiers in Psychology, 6, 1267. https://doi.org/10.3389/fpsyg.2015.01267.

Zamani, Z. (2016). The woods is a more free space for children to be creative; their imagination kind of sparks out there: Exploring young children's cognitive play opportunities in natural, manufactured, and mixed outdoor preschool zones. Journal of Adventure Education and Outdoor Learning, 16(2), 172-189. https://doi.org/10.1080/14729679.2015.1122538. 